\title{
A Hierarchy of Hu RNA Binding Proteins in Developing and Adult Neurons
}

\author{
Hirotaka J. Okano and Robert B. Darnell \\ Laboratory of Molecular Neuro-Oncology, The Rockefeller University, New York, New York 10021
}

The Hu proteins are a group of antigens targeted in an immunemediated neurodegenerative disorder associated with cancer. We have cloned and characterized four members of the $\mathrm{Hu}$ gene family from mouse. We find that the $\mathrm{Hu}$ genes encode a large number of alternatively spliced transcripts to produce a series of related neuron-specific RNA binding proteins. Despite this complexity, we have discerned several ordered features of $H u$ expression. In the embryo, specific $H u$ genes are expressed in a hierarchy during early neurogenesis. In the E16 developing cortex, $m H u B$ is induced in very early postmitotic neurons exiting the ventricular zone, $m H u D$ is expressed in migrating neurons of the intermediate zone, and $m H u C$ is expressed in mature cortical plate neurons. Such a hierarchy suggests distinct functional roles for each gene in developing neurons. In the adult, all neurons express some set of $\mathrm{Hu}$ mRNA and protein. However, specific patterns are evident such that individual neuronal types in the hippocampus, cerebellum, olfac- tory cortex, neocortex, and elsewhere express from one to several $\mathrm{Hu}$ genes. The complexity of potential protein variants within a gene family and of different $\mathrm{Hu}$ family members within a neuron suggests a diverse array of function. Given the strong homologies among the Hu proteins, the Drosophila neurogenic gene elav, and the Drosophila splicing factor $s x l$, we predict that different combinations of $\mathrm{Hu}$ proteins determine different neuron-specific aspects of post-transcriptional RNA regulation. Our findings of specific developmental patterns of expression and the correlation between immune targeting of the $\mathrm{Hu}$ proteins and adult neurodegenerative disease suggest that the $\mathrm{Hu}$ proteins are critical in both the proper development and function of mature neurons.

Key words: neuron-specific gene expression; paraneoplastic neurologic disease; RNA binding protein; Hu onconeural antigen; autoimmunity
RNA binding proteins specifically expressed in the nervous system have been described in several species, although their functions remain unknown. Two distinct families of mammalian neuronspecific RNA binding proteins (n-RBPs) have been identified as target antigens in the human paraneoplastic neurological disorders (for review, see Darnell, 1996). The Nova family of proteins, identified as target antigens in a paraneoplastic motor disorder (Buckanovich et al., 1993), harbor three KH-type RNA binding domains also found in FMR-1, the fragile $X$ mental retardation gene, and a number of splicing factors (Burd and Dreyfuss, 1994; Arning et al., 1996; Min et al., 1996). Nova-1 functions as an RNA binding protein in vitro and is expressed only in CNS neurons in a restricted pattern during development and adulthood (Buckanovich et al., 1996). The Hu family of proteins was identified as target antigens in a paraneoplastic neurological syndrome (the Hu syndrome) consisting of a diverse set of neuronal degenerations associated with small-cell lung cancer. The defining feature of the $\mathrm{Hu}$ syndrome is the presence of antibodies present in patients' serum and cerebrospinal fluid that recognize antigens present in small-cell lung tumors and in neurons (for review, see Posner, 1995; Darnell, 1996). These antisera have allowed the cloning of

Received Dec. 24, 1996; revised Feb. 3, 1997; accepted Feb. 11, 1997.

These studies were supported by grants to R.B.D. from the National Institute of Neurological Disorders and Stroke (RO1 NS34389) and the Irma T. Hirschl Trust. H.J.O. was supported by National Research Service Award Postdoctoral Training Grant CA 09673-18. We thank members of our laboratory for discussion and critical reading of this manuscript. We also thank Geoff Manley and Ron Buckanovich for useful discussions in the early stages of this work.

Correspondence should be addressed to Dr. Robert B. Darnell, Laboratory of Molecular Neuro-Oncology, The Rockefeller University, 1230 York Avenue, New York, NY 10021.

Copyright (C) 1997 Society for Neuroscience $\quad 0270-6474 / 97 / 173024-14 \$ 05.00 / 0$ target antigens, which have been used as defined diagnostic reagents to identify patients with the $\mathrm{Hu}$ syndrome. As a result, it has become clear that many $\mathrm{Hu}$ patients develop neurological degenerations that initially affect discrete areas of the nervous system, including the dorsal root ganglia, the limbic system, cerebellum, brainstem, motor, or autonomic nervous system. Most patients subsequently develop a complex syndrome best characterized as a multifocal neuronal degeneration and die from neurological causes, on average, seven months from the time of their diagnosis (Dalmau et al., 1991).

$\mathrm{Hu}$ antisera recognize a nuclear antigen present in all neurons but not expressed in other tissues (Graus et al., 1985; Dalmau et al., 1992). Hu antisera also recognize a set of antigens of $M_{\mathrm{r}} 35-40$ $\mathrm{kDa}$ on Western blots of brain or tumor extracts and were used to clone a brain cDNA, termed $H u D$, encoding a target antigen (Szabo et al., 1991). Subsequently, two additional genes encoding target antigens have been identified: $\mathrm{HuC}$ (Szabo et al., 1991) or ple21 (Sakai et al., 1993) and Hel-N1 (Levine et al., 1993), termed here $H u B$; additional antigens are likely to exist (Good, 1995).

The $H u$ family of genes shares homology with the Drosophila elav and sex lethal ( $s x l$ ) genes. These homologies are concentrated in three RNA recognition motifs present in all of the $\mathrm{Hu}$ antigens. The function that $\mathrm{Hu}$ proteins play as RNA binding proteins in the vertebrate nervous system is not known. elav is essential for neurogenesis in flies, whereas $s x l$ regulates alternative splicing of its own and tra transcripts. These observations suggest possible developmental and functional roles for the $\mathrm{Hu}$ proteins. Several in vitro studies have demonstrated that the $\mathrm{Hu}$ proteins bind to RNA. HuB was found to bind to AU-rich RNA sequences in vitro (Levine et al., 1993; Gao et al., 1994). Similar findings subse- 
quently were reported with $\mathrm{HuD}$ and a related protein $\mathrm{HuR}$ (Liu et al., 1995; Ma et al., 1996); recently, the mouse homolog of $\mathrm{HuB}$ has been reported to bind to a GA-rich sequence (Abe et al., 1996). The significance of the AU-rich sequences that $\mathrm{Hu}$ proteins bind could relate to mRNA turnover, although this is uncertain (see Lagnado et al., 1994; Zubiaga et al., 1995); similar AU-rich sequences may be involved in various aspects of RNA metabolism, including the regulation of RNA turnover (Shaw and Kamen, 1986; Zubiaga et al., 1995) and splicing (McMullough and Schuler, 1993).

It is unknown whether the clinical diversity seen in the $\mathrm{Hu}$ syndrome correlates in any way with the molecular diversity of the genes encoding target $\mathrm{Hu}$ antigens. In situ hybridization studies with a probe derived from conserved regions of the $\mathrm{Hu}$ coding sequences (King et al., 1994) are consistent with immunohistochemical observations that the $\mathrm{Hu}$ antibody binds to all neurons (Posner and Furneaux, 1990). However, no study has been made of the expression pattern of individual $H u$ family members by using specific reagents. The diverse number of $\mathrm{Hu}$ genes suggests that individual $\mathrm{Hu}$ transcripts might be expressed at either different developmental times or in specific subsets of neurons. Such studies are not only of importance in developing an understanding of the role that these RNA binding proteins play in the development and function of neurons but in addressing their role as target neuronal antigens in autoimmune neurological disease. For example, it is unknown whether the progression from unifocal to multifocal neurological disease in $\mathrm{Hu}$ patients might correlate with an autoimmune attack against a succession of $\mathrm{Hu}$ antigens.

To address these issues, we have developed gene-specific probes to study the expression and function of $\mathrm{Hu}$ gene family members in the mouse. We have identified four mouse $\mathrm{Hu}$ gene family members (termed $m H u A$ through $m H u D$ ) that encode target antigens reactive with $\mathrm{Hu}$ antisera. Each gene has a complex pattern of alternative splicing, predicting at least 18 different protein variants that can be generated from the four genes. We have used gene-specific in situ hybridization probes to identify marked variability in the expression patterns of each $m H u$ gene within the developing and adult mouse nervous systems. We present evidence that there is a hierarchy of $H u$ expression in early postmitotic neurons, such that $m H u B$ is expressed in the earliest differentiated neurons, followed by $m H u D$ and then $m H u C$. In addition, in the adult CNS there are several neuronal cell types that demonstrate specific expression of individual $\mathrm{Hu}$ family members. On the basis of our data, we conclude that the $\mathrm{Hu}$ proteins are likely to play specific roles in discrete sets of developing and adult neurons, and each may serve as a target antigen in the $\mathrm{Hu}$ neurological syndrome.

\section{MATERIALS AND METHODS}

Degenerate oligonucleotide PCR screening. The published $H u$ family member sequences show extremely high amino acid conservation between members. This sequence conservation is particularly strong $(>95 \%)$ among each of the three 80 amino acid RNA recognition motifs (RRMs) present in each family member. Four sets of degenerate oligonucleotides centering around the conserved eight and six amino acid RNP1 and RNP2 submotifs within each RRM (FP1, 5'-GGI TAT/C GGI/C TTT/C GTI AAC/T TA; FP2, 5'-GGI TTC/T ATI/C C/AGI/C TTT/C GAT/C AA; RP1, 5'-AG/AG/A G/ATT G/ATA I/CAC/T A/GAA IAT; RP2, 5'-TTG/A TCA/G AAI/C CG/TI/C ATA/G AAI CC; I refers to inosine) were used in several combinations and conditions to amplify sequences from human fetal cDNA and human hippocampal cDNA library (Stratagene, La Jolla, CA) DNA. These products were subcloned (TA system, Invitrogen, San Diego, CA) and analyzed by exclusive colony hybridization by using $H u C, H u D$, and $H u B$ (Hel-N1) probes. Human and mouse
cDNA libraries (Stratagene) were screened by using these clones to identify full-length sequences.

Developmental expression of alternatively processed $\mathrm{Hu}$ transcripts. Total RNA was isolated from E10, E16, P8, and adult mouse brain as described (Chomcynski and Sacchi, 1987). Single-stranded cDNA was synthesized with $5 \mu \mathrm{g}$ of total RNA in a standard reverse transcriptase reaction primed by random hexamers (Boehringer Mannheim, Indianapolis, IN). PCR was performed with primers specific for cDNAs of $m H u A$ (P1, 5'-TCACAGTGAAGTTTGCAG; P2, 5'-ATTGACACCAGAAATCCC), $m H u B$ (P1，5'-TCACTGTAAAGTTTGCTA; P2, 5'-ATTAATTCCAGCCAGACT), $m H u C$ (P1, 5'-TCAGCGTCAAGTTCGCAA; P2, 5'-GCCACTCATGCCATCGAT), and $m H u D$ (P1, 5'-TTACTGTGAAGTTTGCCA; P2, 5'-GATGTTCATTCCCACAAG) surrounding the coding region between RRM 2 and RRM 3. PCR reactions containing 2.5 $\mu \mathrm{Ci}$ of deoxycytidine $5^{\prime}\left[\alpha^{-32} \mathrm{P}\right]$ triphosphate were run for 33 cycles $(30 \mathrm{sec}$ at $94^{\circ} \mathrm{C}, 30 \mathrm{sec}$ at $58^{\circ} \mathrm{C}$, and $45 \mathrm{sec}$ at $72^{\circ} \mathrm{C}$ ), and $10 \%$ of the reaction was run on $10 \%$ polyacrylamide gel electrophoresis and exposed to XAR-5 autoradiography film. PCR products were subcloned and sequenced to confirm their identity.

In situ hybridization. Protocols for hybridizations were essentially as described (Gibbs and Pfaff, 1994). Sense and antisense RNA probes (250-350 bp) from $3^{\prime}$-UTR of the mouse $\mathrm{Hu}$ clones were transcribed in vitro with T7 RNA polymerase and $\left[{ }^{33} \mathrm{P}\right]$-UTP. Slides were incubated at $50^{\circ} \mathrm{C}$ for $30 \mathrm{hr}$ in a moist chamber with $1 \times 10^{6} \mathrm{cpm}$ of labeled probe per $50 \mu \mathrm{l}$ of hybridization solution. Slides were dipped in Kodak NTB2 emulsion, exposed in the dark for 7-10 d, developed, and counterstained with cresyl violet.

Fusion proteins. cDNAs encoding each $\mathrm{Hu}$ family member were cloned into pET21a (Novagen, Madison, WI) such that each was in an open reading frame encoding the $\mathrm{T} 7$ epitope at the $\mathrm{N}$ terminus with a histidine tag at the $\mathrm{C}$ terminus. After transformation of each construct into Escherichia coli BL21(DE3)pLysS, the bacteria were grown in LB broth at $37^{\circ} \mathrm{C}$ for a few hours and induced with $1 \mathrm{~mm}$ isopropyl thiogalactoside. Fusion proteins were purified by nickel-chelation chromatography.

Affinity purification of antibody. The full-length $\mathrm{HuC}$ fusion protein was coupled covalently to cyanogen bromide Sepharose 4B (Pharmacia, Uppsala, Sweden) according to the manufacturer's instructions. Hu antiserum $(10 \mathrm{ml})$ was spun at $40,000 \times g$ to remove precipitates, and the supernatant was incubated with $2 \mathrm{ml}$ of $\mathrm{Hu}$ fusion protein-cyanogen bromide Sepharose overnight in RIPA buffer ( $150 \mathrm{~mm} \mathrm{NaCl}, 50 \mathrm{~mm}$ Tris, pH 7.4, 0.1\% SDS, $0.1 \%$ Nonidet P-40, and $0.5 \%$ deoxycholate). Sepharose was washed five times in $50 \mathrm{ml}$ of RIPA, column-eluted with $4 \mathrm{ml}$ of $0.2 \mathrm{M}$ glycine, $\mathrm{pH} 2.0$, neutralized with $1 \mathrm{~m}$ Tris, $\mathrm{pH} 9.5$, and dialyzed against PBS.

Northern blot analysis. Total RNA $(15 \mu \mathrm{g})$ from the indicated mouse tissues was run on the $1 \%$ agarose-formaldehyde gel and transferred onto nylon filters (Amersham, Arlington Heights, IL). Probe was prepared by random prime labeling (Prime-It; Stratagene) of 3' UTR fragments of $m H u A$ or $m H u C$ cDNA and hybridized in $50 \%$ formamide at $42^{\circ} \mathrm{C}$ for 24 $\mathrm{hr}$. Stringent washes were in $0.1 \times \mathrm{SSC}, 0.1 \% \mathrm{SDS}$ at $55^{\circ} \mathrm{C}$, and XAR film exposure was for $72 \mathrm{hr}$.

Immunohistochemistry. Adult female mice were anesthetized with ether and were perfused with saline, followed by $4 \%$ paraformaldehyde for $4 \mathrm{hr}$, and then placed in a $10 \%$ sucrose/PBS solution at $4^{\circ} \mathrm{C}$ overnight. Frozen sections $(11 \mu \mathrm{m})$ were cut in the sagittal plane through the cerebellum and cortex, incubated in $0.3 \% \mathrm{H}_{2} \mathrm{O}_{2}$, and washed with PBS. Subsequently, sections were incubated with primary antibody (affinity-purified Hu antiserum diluted 1:500 or rabbit anti-glial fibrillary acidic protein (GFAP) diluted $1: 300$ in $1 \%$ goat serum, PBS) for $48 \mathrm{hr}$ at $4^{\circ} \mathrm{C}$. Immunoreactivity was visualized via the avidin-biotin-HRP technique (Vectastain Elite Kit, Vector Laboratories, Burlingame, CA), with final incubation in $0.05 \%$ 3-3'-diaminobenzidine tetrahydrochloride with $0.01 \% \mathrm{H}_{2} \mathrm{O}_{2}$ in $0.05 \mathrm{M}$ Tris buffer and counterstained in cresyl violet. For immunofluorescence, sections were incubated with secondary antibodies (FITC antirabbit and rhodamine anti-human; Vector) for $1 \mathrm{hr}$ and washed three times in PBS.

\section{RESULTS}

\section{Cloning of mouse $\mathrm{Hu}$ gene family members}

To obtain gene-specific probes for analysis of the expression of $\mathrm{Hu}$ family members during mouse development, we used degenerate oligonucleotide primers derived from a conserved region of the $\mathrm{Hu}$ genes for PCR amplification of cDNA, coupled with traditional low-stringency cDNA screening, to identify four full-length 
A
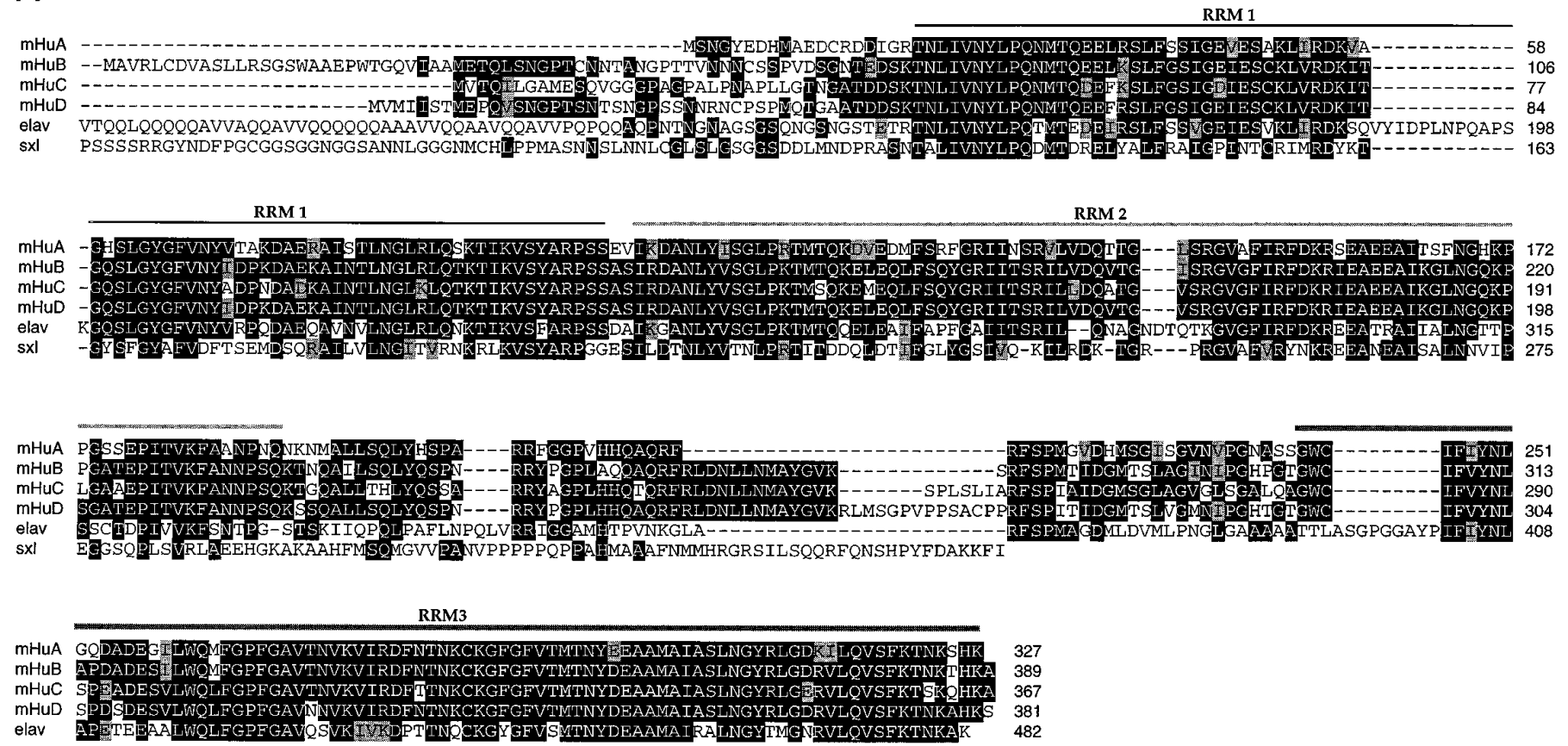

B

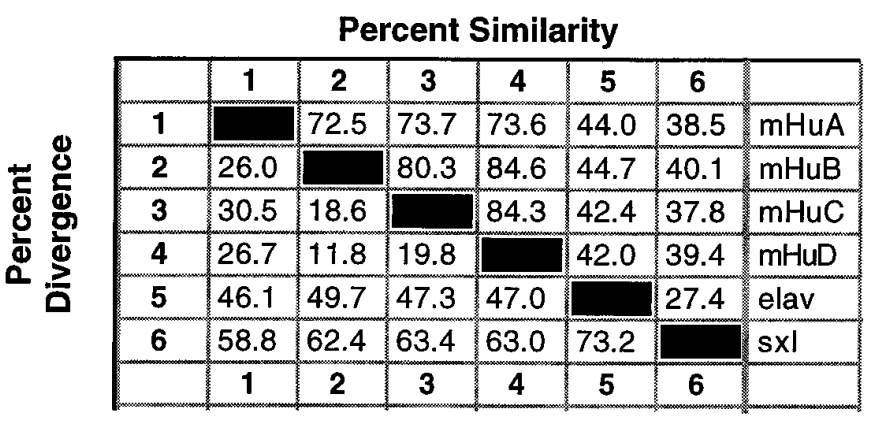

C

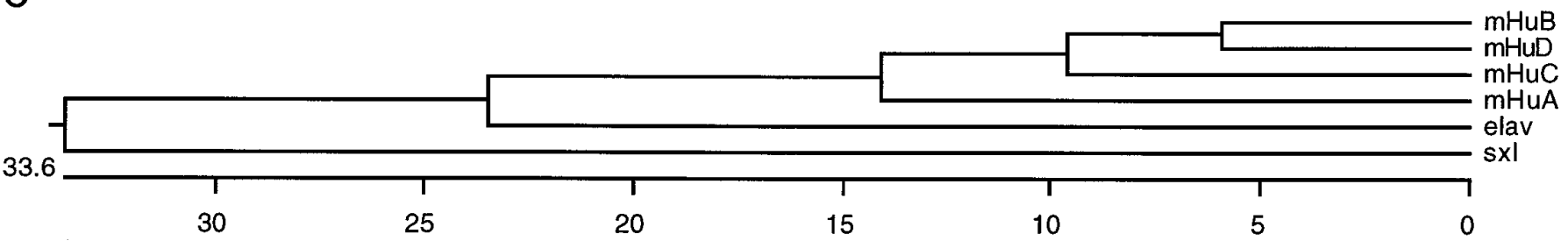

Figure 1. A, Amino acid alignments of Hu-related proteins. The deduced amino acid sequence for four mouse $H u$ genes $(m H u A, m H u B, m H u C, m H u D)$ is compared with the Drosophila elav and sxl genes. Residues identical to the consensus are shown in bold type, and conservative substitutions are shown gray-shaded. The extent of RNA recognition motifs (RRM) 1-3 is indicated. B, Sequence distances between mHu proteins and the Drosophila elav and $s x l$ proteins. Numbers shown represent percentage of similarity or percentage of divergence between the sequences shown in $A$. Amino acid sequences were aligned by using the Megalign program in the DNASTAR software package. $C$, Phylogenetic tree comparing the ancestral relationships between the $\mathrm{mHu}$ proteins and the Drosophila elav and sxl proteins. The scale beneath the tree measures sequence distances. The sequence relationships were determined by using the Megalign program to compare the sequences shown in $A$.

mouse genes $(m H u A-D)$ encoding $H u$ family members. Figure $1 A$ shows the alignment of the predicted proteins of the four $m \mathrm{Hu}$ genes identified via this approach. These include mouse homologs of several mammalian and Xenopus $H u$ genes: $m H u A$ [corresponding to the Xenopus elrA (Good, 1995) and human HuR (Ma et al., 1996) genes], $m \mathrm{HuB}$ (homologous to human Hel-N1; Levine et al., 1993), $\mathrm{mHuC}$ [corresponding to the human $\mathrm{HuC}$ gene (Szabo et al., 1991), also known as ple21 (Sakai et al., 1993)], and $m H u D$ (corresponding to the human $H u D$ gene; Szabo et al.,
1991). In each case there is extremely high sequence homology between individual family members within and across species. This homology is greatest in the RNA recognition motifs (RRM), including RRM 1 and RRM 2, regions thought to encode the $\mathrm{Hu}$ antigenic epitopes (Manley et al., 1995). Moreover, the region of greatest variability between the predicted proteins, and thereby potentially a region related to gene-specific function, lies in the spacer region between RRM 2 and RRM 3. The mouse $H u$ genes are highly homologous to the Drosophila elav and sxl proteins, as 


\begin{tabular}{|c|c|}
\hline Variant & Sequence \\
\hline \multicolumn{2}{|l|}{$H u A$} \\
\hline sv4 & $\mathrm{QRFR}---------------------------\mathrm{FSP}$ \\
\hline \multicolumn{2}{|l|}{$H u B$} \\
\hline sv2A & QRFRLDNLLNMAYGVKR--------------FSP \\
\hline sv2B & QRFRLDNLLNMAYGVKR--------------FSP \\
\hline sv4 & $\mathrm{QRFR}---------------------------\mathrm{FSP}$ \\
\hline \multicolumn{2}{|l|}{$\mathrm{HuC}$} \\
\hline sv1 & QRFRLDNLLNMAYGVKS-------PLSLIARFSP \\
\hline sv2 & QRFRLDNLLNMAYGVKR--------------FSP \\
\hline sv3 & $\mathrm{QRFR}--------------------\mathrm{P}$ LSLIARF SP \\
\hline sv4 & $\mathrm{QRFR}---------------------------\mathrm{FSP}$ \\
\hline \multicolumn{2}{|r|}{ 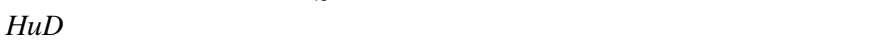 } \\
\hline sv1 & QRFRLDNLLNMAYGVKRLMSGPVPP SACPPRFSP \\
\hline sv2 & QRFRLDNLLNMAYGVKR---------------FSP \\
\hline sv4 & $\mathrm{QRFR}---------------------------\mathrm{FSP}$ \\
\hline
\end{tabular}

Splice variants 1-4 from the spacer region between RRM 2 and RRM 3 (as illustrated in Fig. $2 A$ ) are shown. Variants from each gene are named on the left, and sequences are shown in single-letter amino acid code, with gaps as hyphens. Alternate splice junctions were confirmed by cloning and sequencing mouse genomic clones (data not shown).

noted for previously cloned $H u$ genes. An analysis of the similarity of these genes (Fig. $1 B$ ) indicates that, of the four $m H u$ genes, $m H u A$ is the most closely related to both elav and sxl. Similarly, analysis of the evolutionary relationship among these genes (Fig. 1C) suggests that the ancestral $H u$ gene is $m H u A$, and the most recently diverged members are $m H u B$ and $m H u D$.

\section{Alternative splicing in the $\boldsymbol{H u}$ gene family}

A series of alternatively spliced transcripts was identified during the course of cDNA cloning, including splice variants in both the coding sequence and untranslated regions (UTRs). Numerous splice variants for the $m H u$ genes were found to be restricted to the spacer region, including some previously identified splice variants (Szabo et al., 1991; Gao et al., 1994; Liu et al., 1995). To explore the splicing variation in this region systematically and to confirm the existence and distribution of each coding variant in the developing and adult nervous system, we performed RT-PCR analysis of brain RNAs, using PCR primers flanking this spacer region. Using primers specific to each of the four $\mathrm{Hu}$ genes, we demonstrated that amplified cDNA products were derived from RNA in an RT-dependent manner and confirmed their identity by cloning and sequencing the PCR products (Fig. 2A). The $H u B$ gene produced a splice variant (previously reported as Hel-N2; Gao et al., 1994) for which the expression was restricted to mouse embryogenesis, whereas $H u C$ and $H u D$ produced splice variants expressed during development of the nervous system and in adulthood. Figure $2 B$ shows the spectrum of coding region variants that were identified. In each case splicing variants conform to a specific pattern in which one splice donor (the coding sequences of which end in QRFR) is spliced alternatively to one of three different splice acceptors (Table 1). The $m H u C$ transcript uses one unique splice acceptor to generate splice variant 3 and shows the highest degree of complexity of spacer region alternative splice variants throughout development. We confirmed that the sequence variation corresponded to alternative splicing by sequencing genomic $m H u B$ and $m H u C$ clones (data not shown), which showed the same intron structure in this region as previously reported for the human $H u D$ gene (Liu et al., 1995).
Numerous splice variants also were found in the noncoding region of $H u$ gene family members (Fig. 2C). These include transcripts with alternative start codons in $m H u B$ and $m H u C$ yielding potential additional protein variants (Fig. $2 C$ ); such a variant $5^{\prime}$ end also was found to be encoded in human $\mathrm{HuA}$ transcripts but was not found in the mouse (data not shown). The 3' UTR coding variants included alternative polyadenylation sites $(m H u A$ and $m H u B)$ and true alternative exon usage $(m H u B)$. These observations suggest that the $H u$ noncoding regions may play specific roles in the post-transcriptional regulation of the $\mathrm{Hu}$ mRNAs (see below). The complexity of the UTR splicing variation in the $m H u$ genes increases in relation to the apparent evolutionary age of each gene family member. Thus $H u B$, the presumed ancestral $m H u$ gene, shows the greatest complexity of UTR splice variants (4).

\section{Hu expression}

The expression of the human $\mathrm{Hu}$ antigen has been reported to be restricted to brain (Dalmau et al., 1992), and expression of several $\mathrm{Hu}$ genes has been reported to be neuron-specific, with the exception of $m H u B$ mRNA, which also may be weakly expressed in testis (King et al., 1994), and $m H u A$ homologs, which were reported to be ubiquitously expressed in human and Xenopus tissues (Good, 1995; Ma et al., 1996). Because ubiquitous expression of $H u A$ would seem incongruous with the reported neuronspecific expression of the $\mathrm{Hu}$ antigen, we evaluated both the expression of the $\mathrm{Hu}$ antigen by immunohistochemical and Western blot analysis and expression of the $\mathrm{mHuA}$ gene. Immunohistochemical analysis of E16 mouse embryos, including several neuronal and non-neuronal tissues, demonstrated intense reactivity with the $\mathrm{Hu}$ antigen in all neurons of the central and peripheral nervous systems but no reactivity with non-neuronal tissues, consistent with previous reports (Fig. 3; Posner and Furneaux, 1990; Dalmau et al., 1992; Marusich et al., 1994; Barami et al., 1995). Hu-positive cells had the morphology of neurons in the adult (Fig. $3 I$ ); interestingly, newly born periventricular neurons present in the E16 cortex showed predominantly cytoplasmic staining (Fig. $3 H$ ), whereas adult neurons showed both strong nuclear and cytoplasmic staining (Fig. 3I). To demonstrate whether this reactivity was restricted to neurons, we double-stained sections with GFAP and $\mathrm{Hu}$ antisera. $\mathrm{Hu}$ and GFAP reactive cells were mutually exclusive (Fig. 3J).

We also examined $\mathrm{Hu}$ antigen expression by Western blot analysis. When protein extracts from multiple mouse tissues were run on SDS-PAGE and probed with $\mathrm{Hu}$ antisera, immunoreactive proteins were detected only in brain extracts (Fig. 4A), consistent with a similar analysis of human tissues (Dalmau et al., 1992). One explanation for the observed restricted $\mathrm{Hu}$ antigen expression and the broad distribution of $\mathrm{HuA}$ homolog mRNAs is that the $\mathrm{HuA}$ genes may encode a protein that is not reactive with $\mathrm{Hu}$ antisera (Ma et al., 1996). We examined this possibility by expressing full-length coding sequence for the $\mathrm{mHu}$ genes as bacterial fusion proteins and by probing Western blots with $\mathrm{Hu}$ antisera. The $\mathrm{mHuA}$ fusion protein was reactive at high titer with $\mathrm{Hu}$ antisera, but not with control antisera (Fig. $4 A$; data not shown). When we compared the reactivity of the four $\mathrm{mHu}$ fusion proteins, we found that each was reactive at high titer with $\mathrm{Hu}$ antisera obtained from three different $\mathrm{Hu}$ patients but showed no reactivity with control serum (Fig. 4B; data not shown). Because we also found similar immunoreactivity with each of the four human $\mathrm{Hu}$ fusion proteins (data not shown), we conclude that each of the four $\mathrm{Hu}$ genes encodes potential autoantigens in the $\mathrm{Hu}$ paraneo- 
A

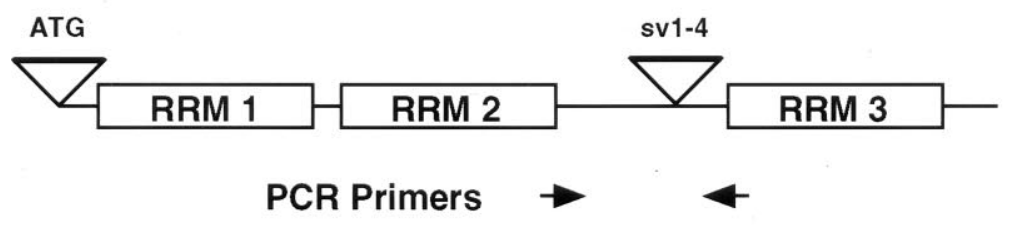

B

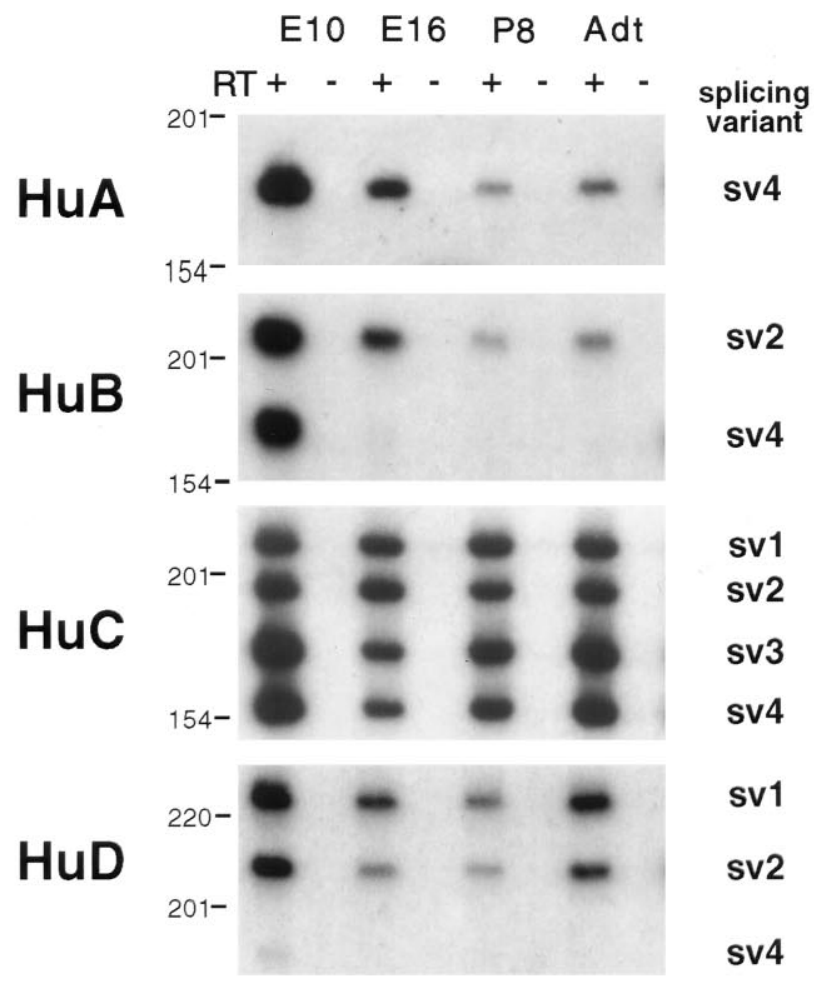

C

5' UTR
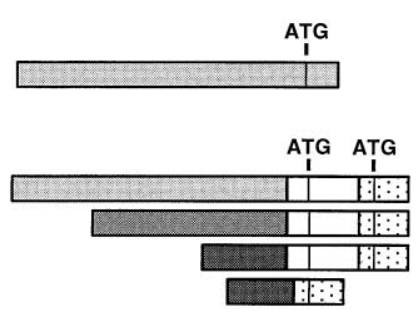

HuB
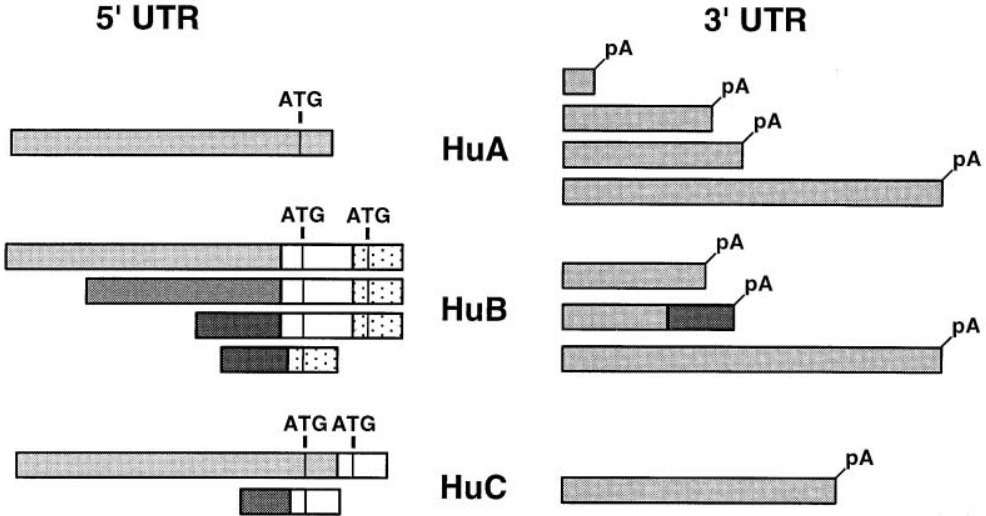

HuC
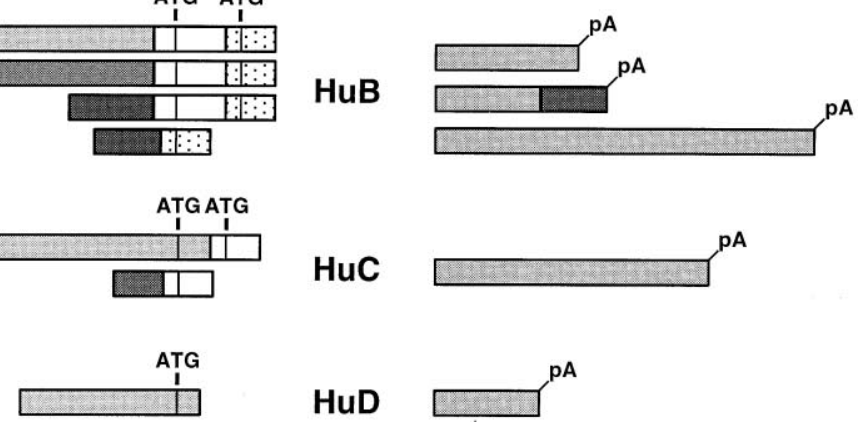

HuD

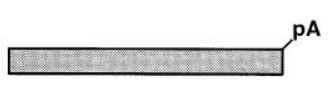

Figure 2. Alternative splicing of mouse $H u$ transcripts. $A$, Location of alternative splicing in $H u$ transcripts and the origin of primers for PCR. Two alternative splicing sites are shown. The site labeled $A T G$ includes splice variants encoding alternative start codons, and the site labeled sv1-4 includes splice variants within the spacer region between $R R M 2$ and $R R M$ 3. B, Developmental analysis of splice variants $s v 1-4$ by RT-PCR. Total RNA from the mouse brain of indicated developmental stage was reverse-transcribed with (lanes marked +) or without (lanes marked -) RT and amplified by PCR with gene-specific primers, the locations of which are indicated by arrows in $A$. The name of each splicing variant is indicated and corresponds with the labels used in Table 1. Because sv2A and sv2B of $H u B$ are not able to be distinguished by RT-PCR, both simply are named as $s \nu 2$ here. DNA size markers are shown on the left (in bp). $C$, Schematic drawing of $H u$ UTR alternative splice variants. $A T G$ indicates putative initiation codons, and $p A$ indicates polyadenylation sites found in cDNA clones. There is no apparent correlation between $5^{\prime}$ or $3^{\prime}$ UTR sequences between $\mathrm{Hu}$ families. plastic disorder. The apparent antigenicity of each gene product varies; when $\mathrm{Hu}$ immunoreactivity was normalized for the amount of fusion protein present in each assay (assessed with a T7 antibody directed against each $\mathrm{Hu}$ fusion protein; Fig. $4 B$ ), we found that the $H u C$ gene encoded the most immunoreactive and $m H u A$ the least immunoreactive epitope, differing by a factor of $\sim 5$ (assessed by densitometry; data not shown). The greater sensitivity of our Western assay may account for the discrepancy 

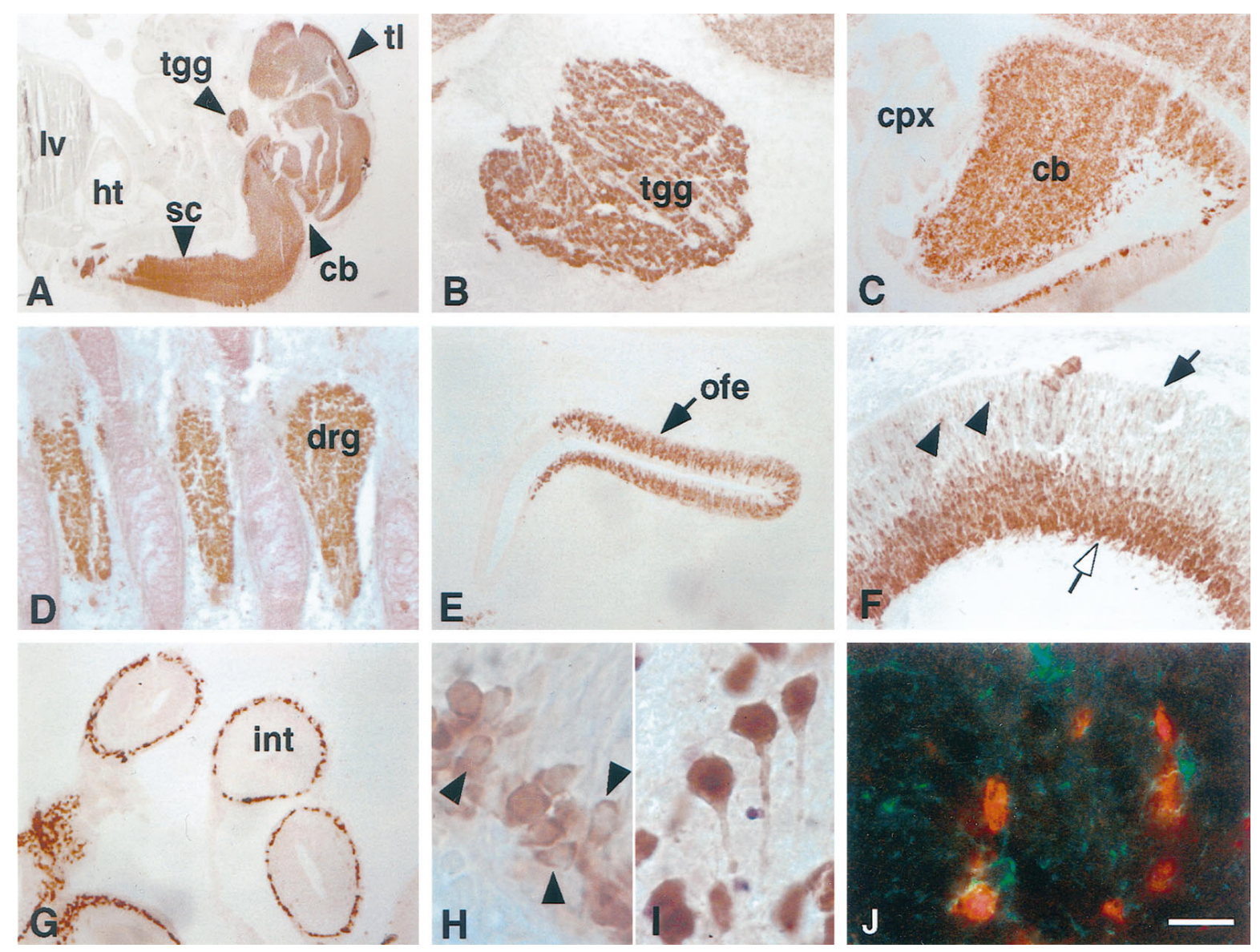

Figure 3. Distribution of Hu immunoreactivity in the E14 and adult mouse. $A$, Sagittal section $(11 \mu \mathrm{m})$ from E14 mouse stained with affinity-purified $\mathrm{Hu}$ antiserum. There is intense immunoreactivity in the central and peripheral nervous systems, including the telencephalon, cerebellum, and spinal cord, but no reactivity in other tissues, including liver and heart. $B$, Hu immunoreactivity in E14 trigeminal ganglia. $C$, Hu immunoreactivity in E14 cerebellum, demonstrating intense staining in the developing cerebellum with no staining of the choroid plexus. $D$, Hu immunoreactivity in E14 dorsal root ganglia. $E, \mathrm{Hu}$ immunoreactivity in E14 olfactory epithelium. $F$, Hu immunoreactivity in E14 retina; Hu staining is intense in ganglion cell layer (open arrow) but absent in the ventricular surface (solid arrow), except in some scattered cells (arrowheads). G, Hu expression in the ganglion cells in the small intestine. $H$, High-power magnification of Hu immunoreactivity in E14 cortex. Note the cytoplasmic staining in the developing cells (arrowheads). I, High-power magnification of $\mathrm{Hu}$ immunoreactivity in a horizontal section $(11 \mu \mathrm{m})$ of adult cortex, demonstrating that Hu reactivity in the differentiated neuron is both nuclear and cytoplasmic (arrows). $J$, Immunofluorescence double exposure of GFAP (green) and $H u$ (red) immunoreactivity in a horizontal section of adult cortex, demonstrating that the two are mutually exclusive. $t l$, Telencephalon; tgg, trigeminal ganglia; $s c$, spinal cord; $c b$, cerebellum; $h t$, heart; $l v$, liver; $c p x$, choroid plexus; $d r g$, dorsal root ganglia; ofe, olfactory epithelium; int, small intestine. Scale bars: $2 \mathrm{~mm}$ in $A ; 160 \mu \mathrm{m}$ in $B-E, G ; 80 \mu \mathrm{m}$ in $F ; 20 \mu \mathrm{m}$ in $H-J$.

between these results and a previous report in which ${ }^{125} \mathrm{I}$ protein-A detection was used to assay the reactivity of $\mathrm{Hu}$ disease antisera with HuA fusion protein (Ma et al., 1996).

Because several reports indicated that mRNA-encoding $\mathrm{HuA}$ homologs were ubiquitously expressed, we evaluated the tissue distribution of $m H u A$ gene expression in the mouse. Northern blot analysis with an $m H u A$ coding region probe to examine mRNA in multiple tissues (Fig. 5) confirmed that $m H u A$ RNA expression could be detected ubiquitously, whereas $m H u C$ expression was restricted to brain. We next examined whether subtle differences in brain versus nonbrain $m H u A$ mRNA, such as small alternatively spliced exons not detectable by Northern blot analysis, could account for the discrepancy between the restricted distribution of the $\mathrm{Hu}$ protein and mRNA. We cloned full-length cDNAs encoding $m H u A$ from a nonbrain (spleen) tissue that does not express immunoreactive $\mathrm{Hu}$ antigen (Fig. $4 A$; data not shown) and compared the sequences with brain $m H u A$ cDNA sequences. These data revealed that the brain and spleen $m H u A$ mRNA were identical within the full coding region and regions of the UTR that were sequenced. We conclude that the discrepancy between the restricted expression of $\mathrm{Hu}$ protein and the widespread expression of the $m H u A$ gene may be a result of post-transcriptional regulation of $m H u A$ gene expression. Such regulation also may occur with $H u B$ expression, because we and others detect no protein expression in ovary or testis (Fig. 4A; Dalmau et al., 1992), whereas others have found expression of $\mathrm{HuB}$ homolog mRNA in these tissues (King et al., 1994; Good, 1995). Finally, we note that determination of the tissue pattern of $\mathrm{mHuA}$ protein expression will need to await the development of specific antibodies.

\section{Tissue and developmental expression of individual $\mathrm{Hu}$ gene family members}

To examine the expression pattern of individual $\mathrm{Hu}$ genes, we performed in situ hybridization with gene-specific probes. Sense and antisense 3' UTR sequences from the cloned $m H u$ genes were transcribed and used to probe sections from developing and adult mice. Figure 6 shows a panel of mouse embryonic and adult sections probed with an antisense riboprobe specific for $m \mathrm{HuC}$. In 

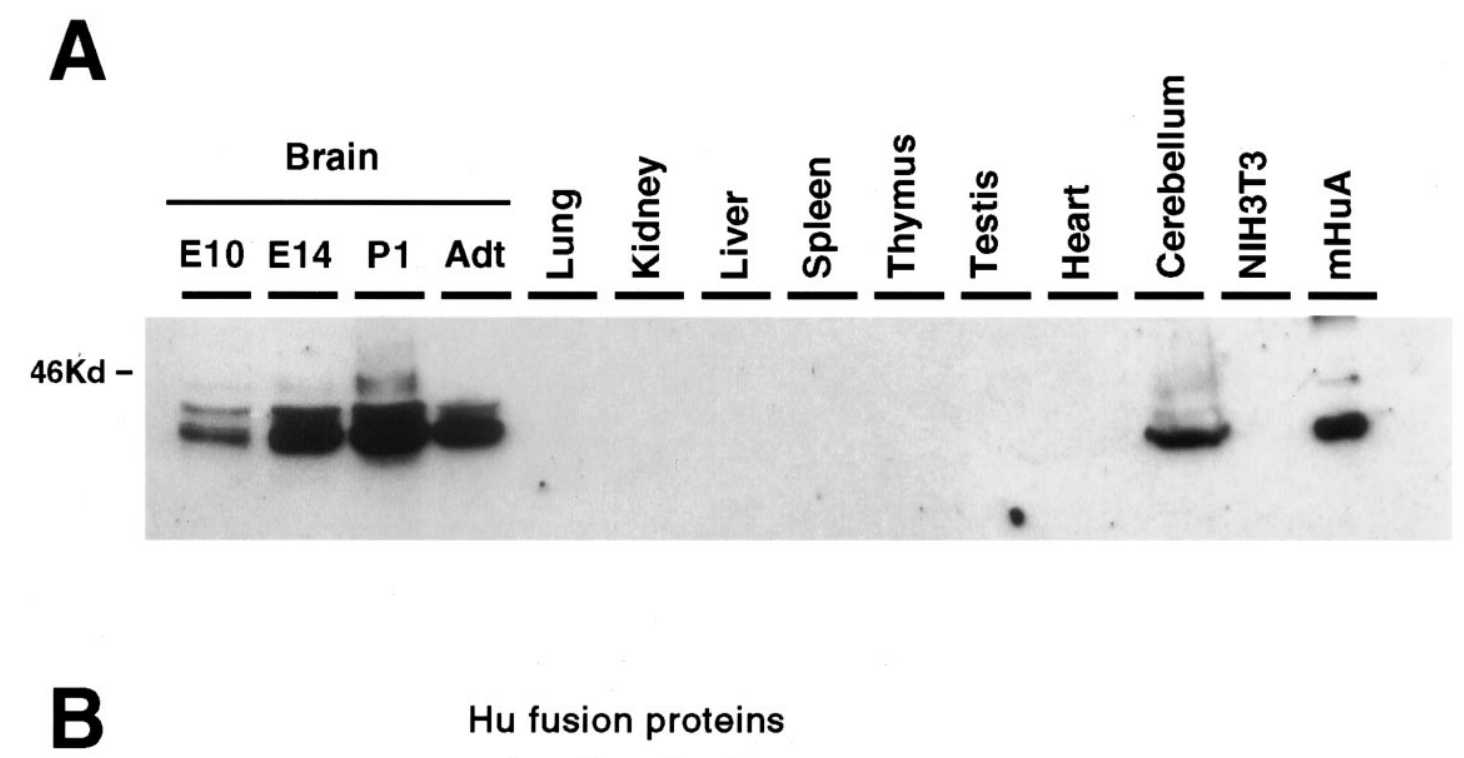

\section{Hu fusion proteins}

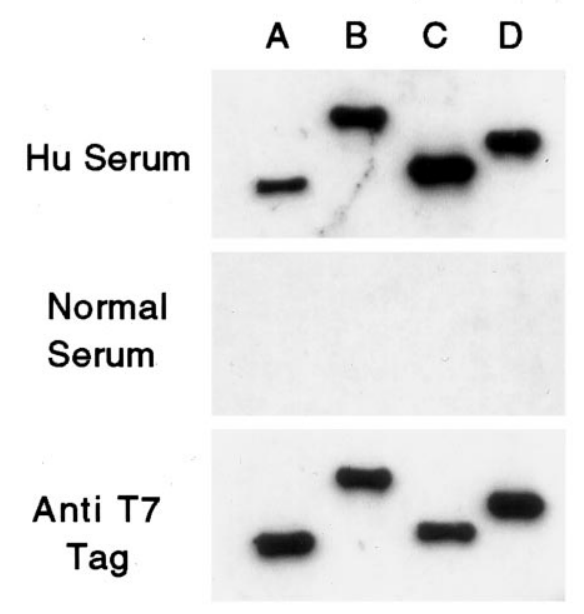

Figure 4. Western blot analysis of $\mathrm{Hu}$ antigen expression in vivo and in vitro. $A$, Hu expression in the developing mouse brain and various adult tissues. Total cellular extracts from the indicated tissues, National Institutes of Health $3 \mathrm{~T} 3$ cells, or purified mouse HuA fusion protein were run on $10 \%$ SDS-PAGE, transferred to nitrocellulose, and probed with $\mathrm{Hu}$ antiserum. The blot also was probed with an anti-tubulin antibody, which revealed that each of the nonbrain samples had at least as much (in most cases greater) protein loaded as in the lanes marked Brain or Cerebellum (data not shown). $B, \mathrm{Hu}$ antiserum recognizes recombinant fusion proteins of all four Hu family members. Equal amounts of T7-tagged bacterial fusion proteins of mouse $H u A, H u B, H u C$, and $H u D$ were probed with paraneoplastic Hu antiserum (Hu Serum). The blot also was probed with normal human serum (Normal Serum), which was not reactive with the Hu fusion proteins, and an anti-T7 tag monoclonal antibody (Anti T7 Tag) used as a positive control and used to normalize the quantity of fusion protein present in each sample. Identical results were obtained with three different Hu disease antisera and Hu antisera affinity-purified with $\mathrm{HuC}$ fusion protein (data not shown).

each section the hybridization pattern is restricted entirely to the nervous system. At E16 it is evident that neurons of the central and peripheral nervous systems express $H u C$ mRNA; there is robust reactivity in the retina, telencephalon, midbrain, hindbrain, and spinal cord and peripheral nervous system, including the trigeminal ganglia and dorsal root ganglia (Fig. $6 \mathrm{~A}$ ). At $\mathrm{P} 0, m \mathrm{HuC}$ expression remains tightly restricted to the nervous system (Fig. $6 B$ ), and in the adult brain there is widespread reactivity restricted to cells of the central and peripheral nervous systems (Fig. 6C). Similar nervous system-specific expression was evident for all $m H u$ probes (except $m H u A$ ) throughout embryogenesis and in adulthood (see below; data not shown).

Immunohistochemical analysis has indicated previously that $\mathrm{Hu}$ protein expression is induced within hours of neurogenesis in the developing avian brain, when it is measured after ${ }^{3} \mathrm{H}$-thymidine or BrdU labeling of early postmitotic neurons (Marusich et al., 1994;
Barami et al., 1995). We compared the early developmental expression of individual $m \mathrm{Hu}$ genes with the expression of the $\mathrm{Hu}$ antigen. We assumed in these studies that the $\mathrm{Hu}$ immunohistochemical pattern is a measure of the sum of all $\mathrm{Hu}$ antigens expressed (see Fig. 3). At E16 in the developing mouse neocortex, immunohistochemical staining with affinity-purified anti-Hu antibody demonstrated robust reactivity in the postmitotic neurons of the cortical plate, in migrating neurons of the intermediate zone, and some reactivity in scattered neurons in the ventricular zone (Fig. 7A). Similarly, developing neurons of the P9 cerebellum showed $\mathrm{Hu}$ immunoreactivity in the inner cells of the external granular layer (EGL), Purkinje neurons, and neurons within the internal granular layer (IGL; Fig. $7 E$ ). We interpret the $\mathrm{Hu}$ immunohistochemical reactivity of a subset of neurons within the EGL and ventricular zone as consistent with previous reports that $\mathrm{Hu}$ protein is induced at the time of neurogenesis. 


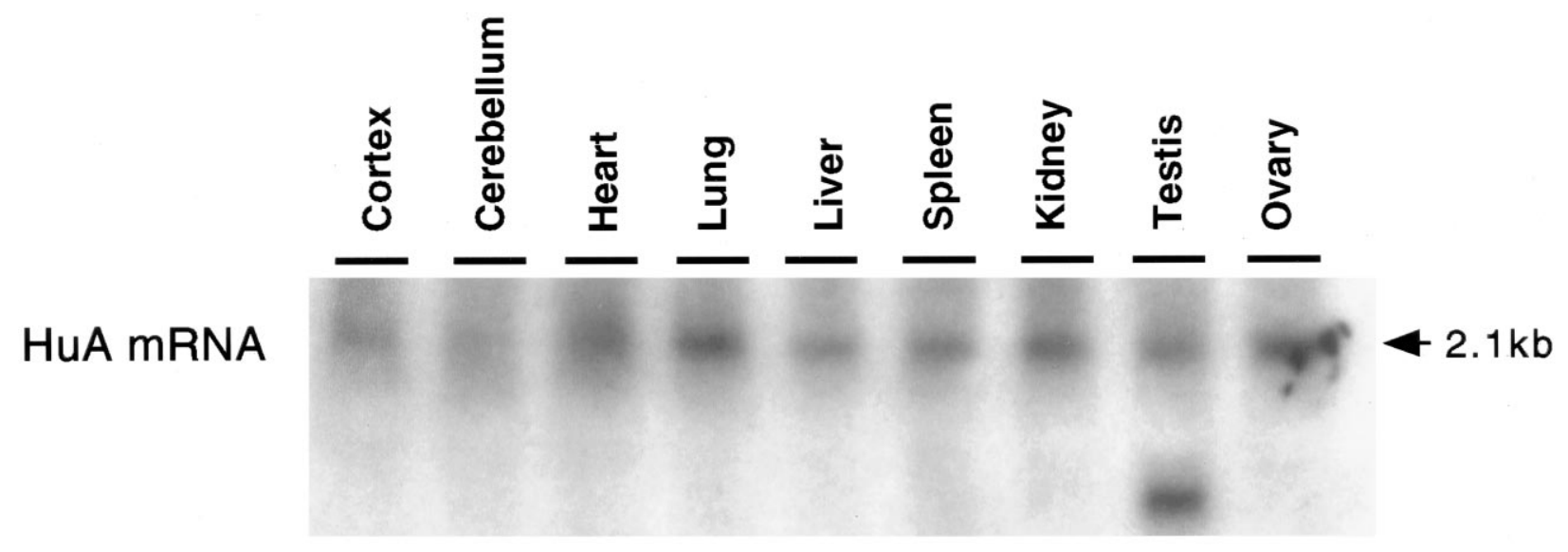

HuC mRNA

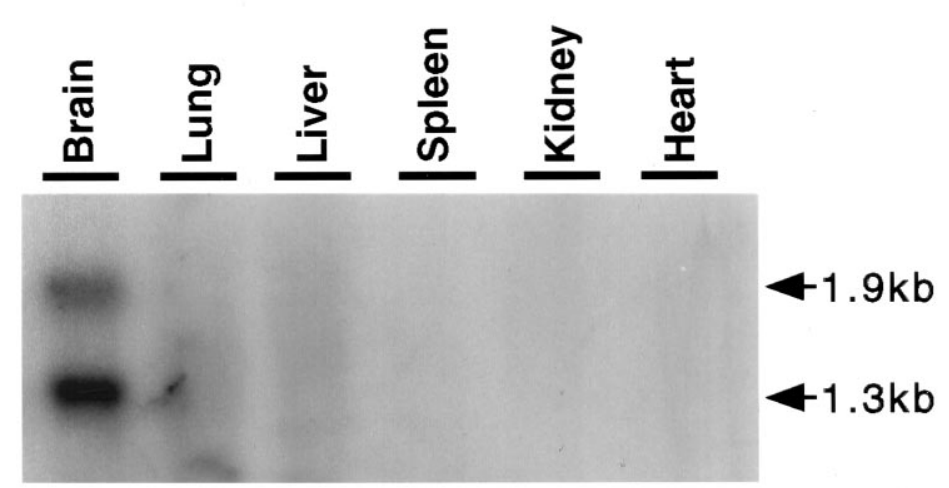

Figure 5. Northern blot analysis of $H u A$ and $H u C$ in various mouse tissues. Fifteen micrograms of total RNA from the indicated adult mouse tissues were separated on an agarose-formaldehyde gel, transferred onto nylon membranes, and hybridized with ${ }^{32} \mathrm{P}-$ labeled $3^{\prime}$ UTR cDNA probes specific for $m H u A$ or $m H u C$. RNAs were visualized with ethidium bromide for examining the equivalent amount of each sample (data not shown).
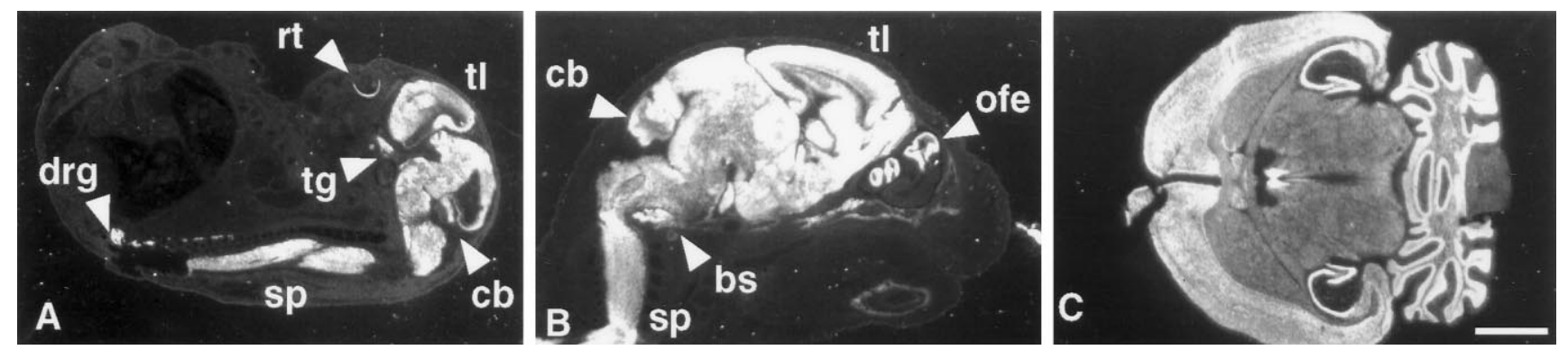

Figure 6. Specific expression of $m H u C$ in the nervous system; dark-field microscopy of $H u C$ in situ hybridization in the mouse. Sagittal sections (11 $\mu \mathrm{m}$ ) of E16 $(A)$ and P0 $(B)$ mouse and a horizontal section $(11 \mu \mathrm{m})$ of adult mouse brain $(C)$ were hybridized with ${ }^{33} \mathrm{P}$-labeled antisense $m H u C$-specific cRNA probe. Mouse $\mathrm{HuC}$ expression is observed in the telencephalon, cerebellum, spinal cord, dorsal root ganglia, and olfactory epithelium at E16 and P0 and is absent in non-neural tissues. Expression in the nervous system persists through adulthood $(C)$ and remains absent in non-neural tissue (data not shown). No reactivity was observed with a sense riboprobe (data not shown). $b s$, Brain stem; $t g$, trigeminal ganglia; $r t$, retina; $t l$, telencephalon; $c b$, cerebellum; $d r g$, dorsal root ganglia; ofe, olfactory epithelium; sp, spinal cord. Scale bar, $2 \mathrm{~mm}$.

\section{Hierarchies of $m H u$ mRNA expression in developing neurons}

Interestingly, the $m H u$ mRNAs showed a hierarchy of expression in developing neocortical and cerebellar neurons. $m H u B$ mRNA was expressed in the very earliest stages of neural development, with neocortical expression evident in the outer layer of cells in the ventricular zone, continuing into neurons of the intermediate zone, and diminishing in neurons of the cortical plate; $\mathrm{mHuC}$ mRNA expression was absent in neurons of the cortical ventricular zone and intermediate zone but was robustly expressed in neurons of the cortical plate (Fig. $7 B, C$ ). $m H u D$ expression showed an intermediate pattern of expression, with mRNA first evident in the intermediate zone neurons and diminishing in cortical plate neurons (Fig. 7D).

A similar pattern of $m H u$ gene expression was evident in neurons of the developing cerebellum. Again, $m H u B$ expression was evident in the most immature neurons of the developing cerebellum, in the inner layer of the EGL, with some expression apparent in neurons migrating through the molecular layer, little or no expression in the IGL, and no expression in Purkinje 


\section{$\mathrm{Hu} \mathrm{Ab}$}
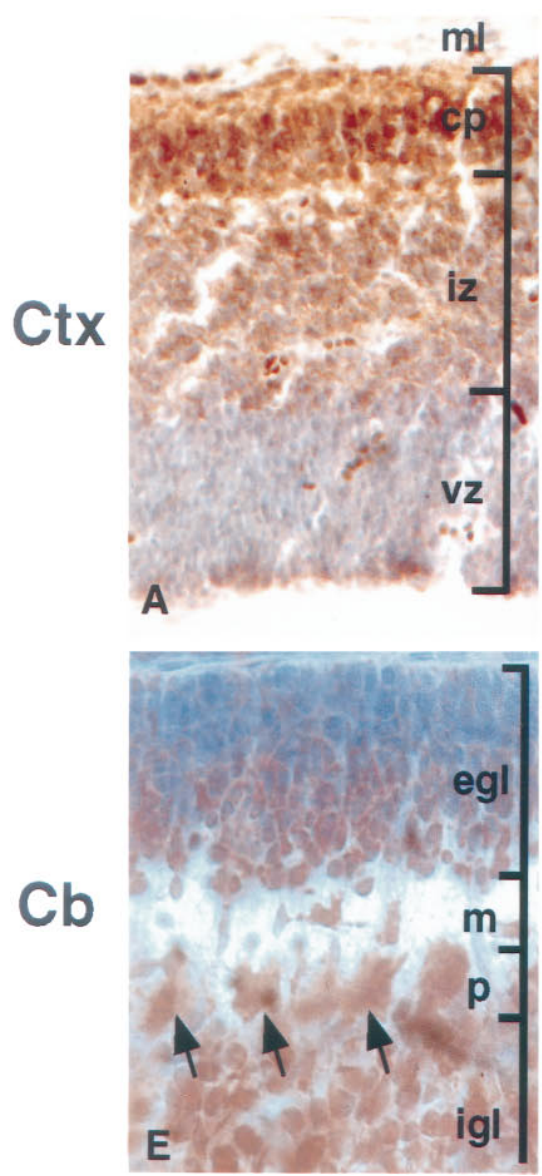

HuB
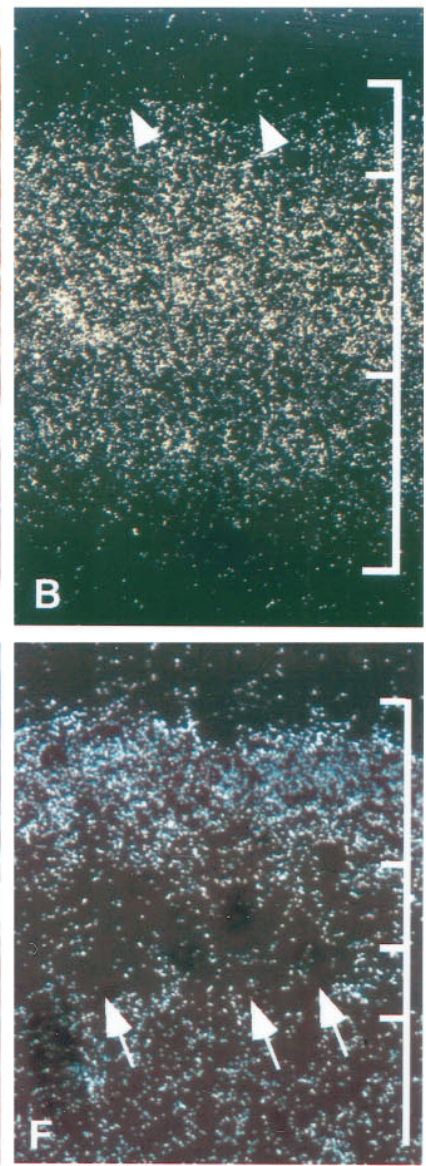

HuC
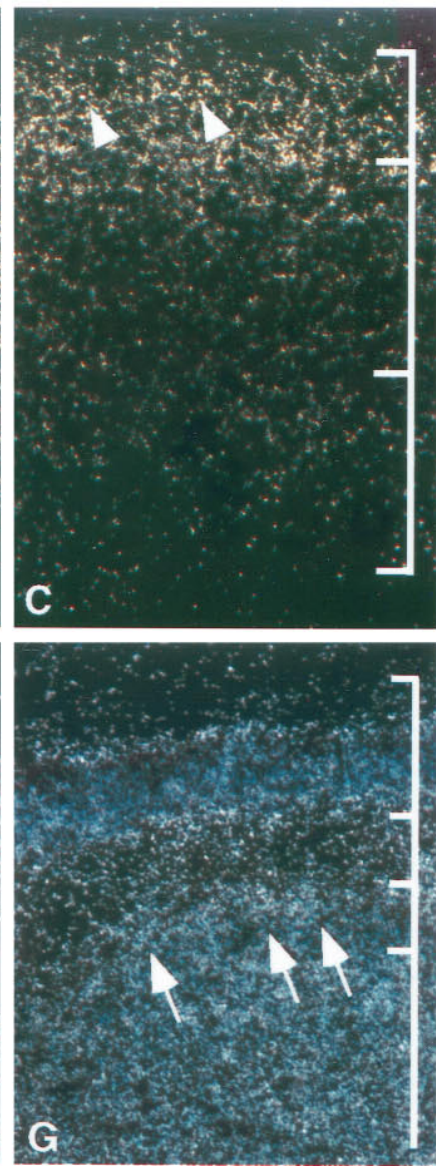

HuD
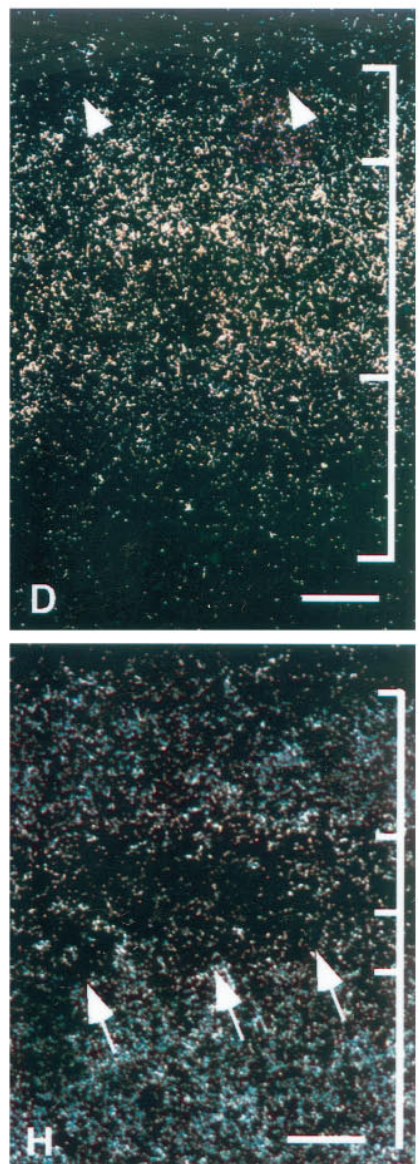

Figure 7. Expression patterns of $H u$ mRNAs in developing brain. Sagittal sections $(11 \mu \mathrm{m})$ of E14 mouse cortex $(C t x ; A-D)$ and P9 mouse cerebellum $(C b ; E-H)$ were analyzed by immunohistochemistry $(A, E)$ and in situ hybridization $(B-D, F-H)$. Affinity-purified Hu antibody was used for immunohistochemistry $(A, E)$. Serial sections were hybridized with ${ }^{33} \mathrm{P}$-labeled antisense $H u B(B, F), H u C(C, G)$, and $H u D(D, H)$ gene-specific $3^{\prime} \mathrm{UTR}$ cRNA probes. In the developing cortex, $m H u B$ is expressed in some cells of the ventricular zone and cells of the intermediate zone; $m H u B$ diminishes in the cortical plate, with no expression evident in the outermost differentiated neurons (arrowheads). $m H u C$ is detected only in the cortical plate, including the differentiated neurons (arrowheads). $m H u D$ expression is intense in the intermediate zone, diminishes in the cortical plate, and is very weak or absent in the differentiated neurons (arrowheads). In developing cerebellum, $m H u B$ is expressed primarily in the external granule cell layer, whereas the expression of $m H u C$ and $m H u D$ is distributed widely. Purkinje cells (arrows) express only $m H u C$. Sections were counterstained with cresyl violet. $m l$, Marginal layer; $c p$, cortical plate; $i z$, intermediate zone; $v z$, ventricular zone; $e g l$, external germinal cell layer; $m$, molecular layer; $p$, Purkinje cell layer; $i g l$, internal granule cell layer. Scale bars: $60 \mu \mathrm{m}$ in $A-D ; 15 \mu \mathrm{m}$ in $E-H$.

neurons (Fig. $7 F$ ). $m H u C$ expression was robust in the mature Purkinje neurons and IGL neurons, but also it was evident in some neurons in the EGL (Fig. $7 G$ ). $m H u D$ expression also was expressed within the developing cerebellum; it clearly was absent from Purkinje neurons, showed only trace expression in the EGL, and was detected at an intermediate level in the IGL (Fig. 7H). These data suggest that the $m H u B$ gene is unique among the $m H u$ genes in being expressed extremely early in neurogenesis and suggest that the immunohistochemical reactivity previously observed in early postmitotic cortical neurons (Marusich et al., 1994; Barami et al., 1995) may have represented the HuB protein.

\section{$m$ Hu mRNA expression in adult brain}

Analysis of the adult neuronal expression of the $m H u$ genes revealed additional regional differences in expression patterns of $m H u B, m H u C$, and $m H u D$ (Fig. 8 and Table 2). Within the hippocampus (Fig. $8 A-C$ ) $m H u B$ showed restricted expression limited to CA2-CA3-CA4 pyramidal neurons, with no staining evident in the dentate neurons or adjacent entorhinal cortex, whereas $m H u C$ expression was present in all neurons throughout this region, and $m H u D$ expression was absent in dentate neurons but concentrated within the pyramidal neurons and adjacent entorhinal cortex. Within the adult olfactory system (Fig. 8D-F) $m \mathrm{HuB}$ was expressed predominantly within large neurons of the olfactory bulb (mitral neurons), with only scattered expression in small granule neurons; there was also robust and specific expression within the accessory olfactory bulb. $m H u D$ showed an overlapping pattern of expression that included mRNA within both olfactory mitral and granule cells, whereas $m H u C$ expression was robust throughout the olfactory system.

Within the neocortex (Fig. 8G-I) $m H u B$ was detectable only in scattered neurons, $m H u C$ was strongly expressed in all neocortical neurons, and $m H u D$ was expressed most prominently in the large projection neurons in layer 5. The expression of both $m H u C$ and $m H u D$ was evident within the medial habenula, whereas $m H u B$ expression was absent (Fig. $8 J-L$ ). Dorsal root ganglia neurons expressed abundant amounts of $m H u B, m H u C$, and $m H u D$, 
whereas neurons within the spinal cord predominantly expressed $m H u C$ (Fig. $8 M-O$ ). In addition, a population of cells present in the spinal cord white matter expresses $m H u C$ mRNA; the identity of these cells is unclear; they do express $\mathrm{Hu}$ protein by immunohistochemical assay and are GFAP-negative (data not shown). In the adult cerebellum (Fig. $8 P-R$ ) $m H u B$ expression is downregulated except for expression within scattered small cells in the granule layer; the identity of these cells is unclear. $m H u D$ shows faint expression in the granule layer, as well as scattered expression in the molecular layer; again, the identity of the latter cells is unclear; they are GFAP-negative (data not shown) and may represent expression in scattered neurons present in the cerebellar molecular layer. $m \mathrm{HuC}$ expression is robust within adult Purkinje and granule neurons (Fig. 8Q). A summary of $m H u$ gene expression is presented in Table 2. The results support the conclusion that $\mathrm{mHuC}$ expression is nearly ubiquitous in mature postmitotic neurons, whereas the cellular distribution and levels of $m H u B$ and $m H u D$ vary widely during development and in adulthood.

\section{DISCUSSION}

\section{The $H u$ gene family encodes a complex set of neuronal RNA binding proteins}

We have used degenerate PCR and standard cDNA cloning to identify four genes encoding mouse homologs of target antigens in the human $\mathrm{Hu}$ paraneoplastic neurological degenerations. Each of these genes produces a complex set of mRNA variants caused by alternative splicing in the coding and noncoding regions and caused by the usage of alternative polyadenylation sites. Although alternative exon usage within the coding region of some $H u$ genes has been noted previously, we have found that the same pattern of alternative exon usage is conserved in three of the four $\mathrm{Hu}$ genes, suggesting that the regulation of splicing at this point is likely to be a significant point in the regulation of $\mathrm{Hu}$ protein function. Splicing variants are able to generate between one and four variant protein species from each of the $H u$ primary transcripts; some additional splice variants $(m H u B$ and $m H u C)$ add $\mathrm{N}$-terminal coding sequence and alternative initiator methionines. In total, the four $\mathrm{Hu}$ genes encode at least 18 different potential protein variants.

Alternative splicing of neuronal mRNAs is a widespread phenomenon; in extreme examples, such as the neuronal neurexin receptor, it is believed that alternative splicing generates several thousand transcripts from three genes (Ullrich et al., 1995). The $\mathrm{Hu}$ genes are unique in this context in that they are RNA binding proteins highly related to $s x l$. sxl acts in Drosophila to regulate alternative splicing of its own pre-mRNA, as well as splicing of the tra pre-mRNA. The high degree of homology between the $\mathrm{Hu}$ genes and $s x l$ (Szabo et al., 1991), the complexity of Hu protein variants, the hierarchical pattern of $\mathrm{Hu}$ expression, and the predominant nuclear localization of the $\mathrm{Hu}$ antigens suggest that the $\mathrm{Hu}$ proteins might act to regulate alternative splicing of neuronal pre-mRNAs. Neuronal pre-mRNAs encoding complex sets of proteins, such as the neurexins or the $\mathrm{Hu}$ proteins themselves in which the expression of multiple mRNA splice variants are regulated within subsets of developing and mature neurons, are potential candidates for targets of $\mathrm{Hu}$ action. Such a function might coexist with a cytoplasmic role for $\mathrm{Hu}$ proteins, including binding of AU-rich elements implicated as $\mathrm{Hu}$ binding sites in vitro (Levine et al., 1993; Gao et al., 1994; Liu et al., 1995; Ma et al., 1996). Finally, different $\mathrm{Hu}$ antigens may serve entirely different func- tions, an issue that could be approached with antibodies that discriminate between family members.

The extensive variability in 5' and $3^{\prime}$ UTR variants in the $H u$ genes may relate to alternative usage of cis-acting control elements, in particular, variation in elements regulating expression of individual $H u$ mRNAs. The strongest support for this possibility comes from analysis of the $m H u A$ gene in which expression of the protein and mRNA is uncoupled, suggesting that $m H u A$ expression is regulated at a post-transcriptional level. One mechanism for restricting $\mathrm{mHuA}$ protein expression to neurons would be the use of a cis-acting element within the $m H u A$ mRNA that participates in regulating neuron-specific translation of the $m H u A$ mRNA; such a neuronal regulatory element has been found in the BTEB mRNA and suggested for the paraneoplastic cdr2 antigen mRNA, both of which are ubiquitously expressed but translated only in neurons and testis (Imataka et al., 1994; Corradi et al., 1997).

\section{The role of Hu proteins in neural development}

The wide variability in the developmental expression of individual $\mathrm{Hu}$ genes suggests that the different $\mathrm{Hu}$ proteins function in different stages in the early development of postmitotic neurons. By using in situ probes capable of distinguishing each $\mathrm{Hu}$ family member, we are able to conclude that the $m H u B$ gene, and to a lesser extent the $m H u C$ gene, functions specifically in the earliest postmitotic neurons. For example, we find that the $m H u B$ gene is expressed in neurons migrating out of the periventricular zone into the intermediate zone. Similarly, $m H u B$ is robustly expressed in the inner layers of the cerebellar EGL (see Fig. 6). Previous autoradiographic studies have shown that the small cells in the superficial layer of the EGL correspond to proliferating cells, whereas the deeper cells, corresponding to $m H u B$ (and to a lesser extent $\mathrm{mHuC}$ )-positive cells, are undergoing initial steps of neuronal differentiation and axon extension (Miale and Sidman, 1961; Fujita, 1967). Because our immunohistochemical analysis also demonstrates $\mathrm{Hu}$ protein expression in these neurons, we propose that the $\mathrm{mHuB}$ protein is the earliest $\mathrm{Hu}$ family member protein expressed after cortical neurogenesis and that $m H u B$, perhaps together with $m H u C$, is the earliest $\mathrm{Hu}$ family member expressed in developing cerebellar granule neurons.

Although we did not perform double labeling with mitotic markers such as BrdU, previous studies have suggested that the $\mathrm{Hu}$ antigen is detectable at or near the time of cell cycle exit in the avian nervous system (Marusich et al., 1994; Barami et al., 1995). More generally, studies of neuronal differentiation in the chick retina demonstrate that neuronal differentiation markers may be induced within minutes of exit from the cell cycle (Waid and McLoon, 1995). Our data indicate that each of the three types of differentiating neurons-early postmitotic, migrating, and mature neurons- of the cortex and cerebellum express a unique combination of $H u$ genes, suggesting a correlation between neuronal development and the function of different sets of $\mathrm{Hu}$ proteins.

In contrast to the expression of $m H u B$, the $m H u C$ gene is expressed nearly ubiquitously in mature postmitotic neurons during development and adulthood. In several regions of the nervous system, $m H u C$ seems to be the only $m H u$ gene family member that is expressed. For example, only $m H u C$ is expressed in cerebellar Purkinje neurons or hippocampal dentate neurons, suggesting a specific role for the protein in these neurons. Similarly, some groups of neurons preferentially express $m H u B$ or $m H u D$, although typically they are coexpressed with $m H u C$. Thus, neurons of the accessory olfactory bulb express $m H u B$, whereas neurons of the habenula, entorhinal cortex, and layer 5 in the neocortex 
HuB
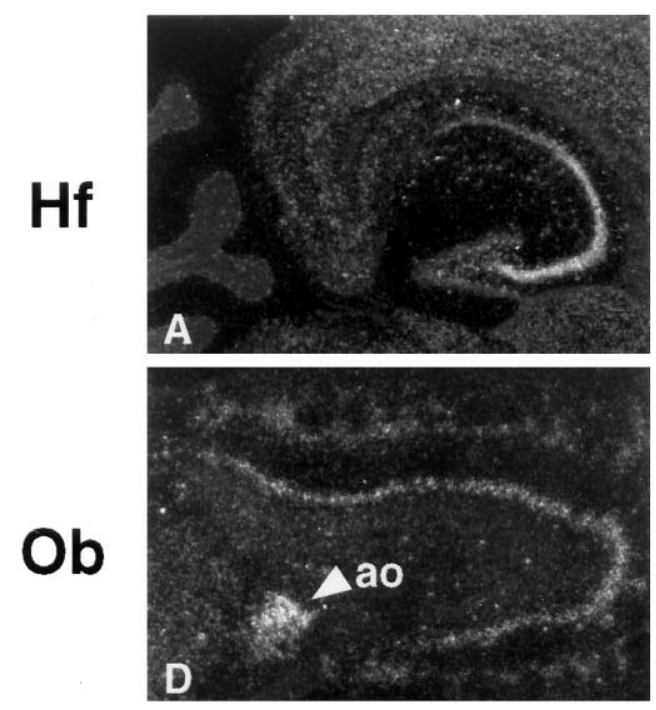

Ctx
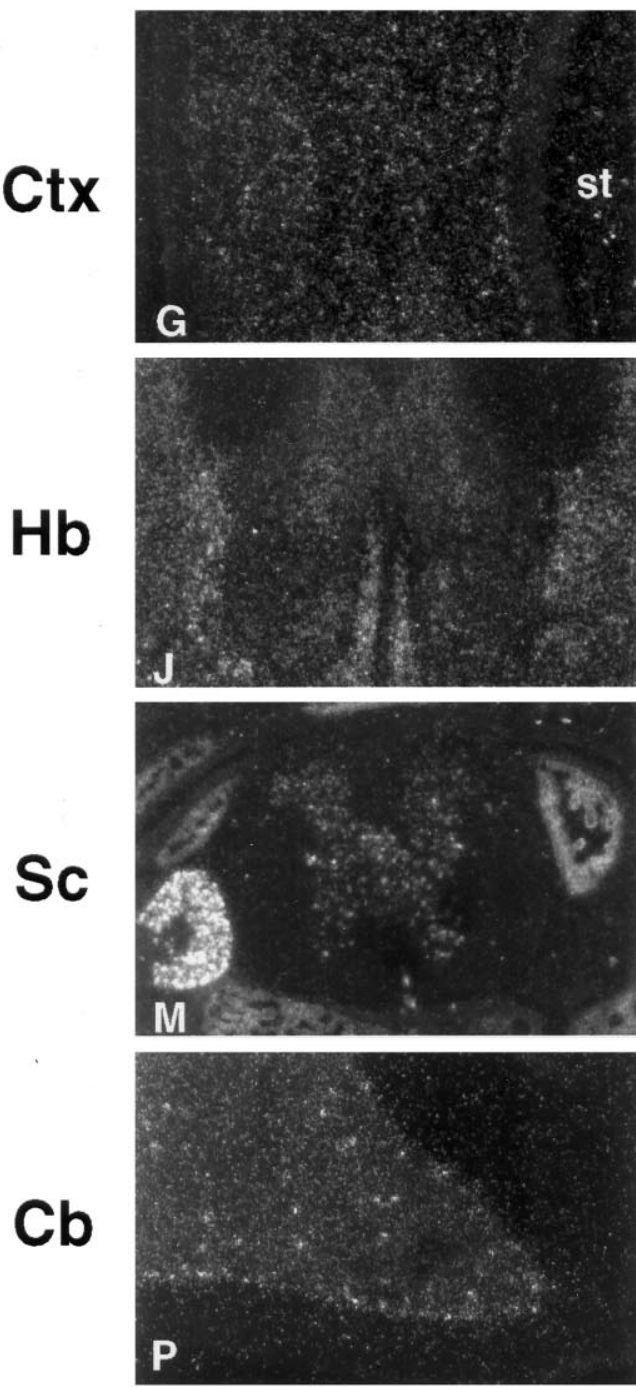

HuC
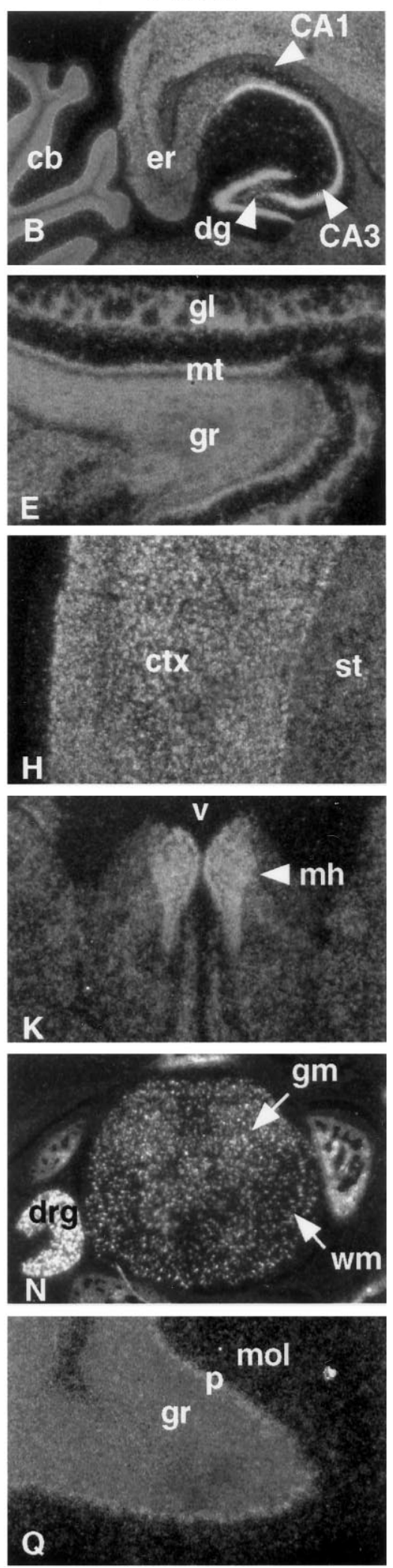

HuD
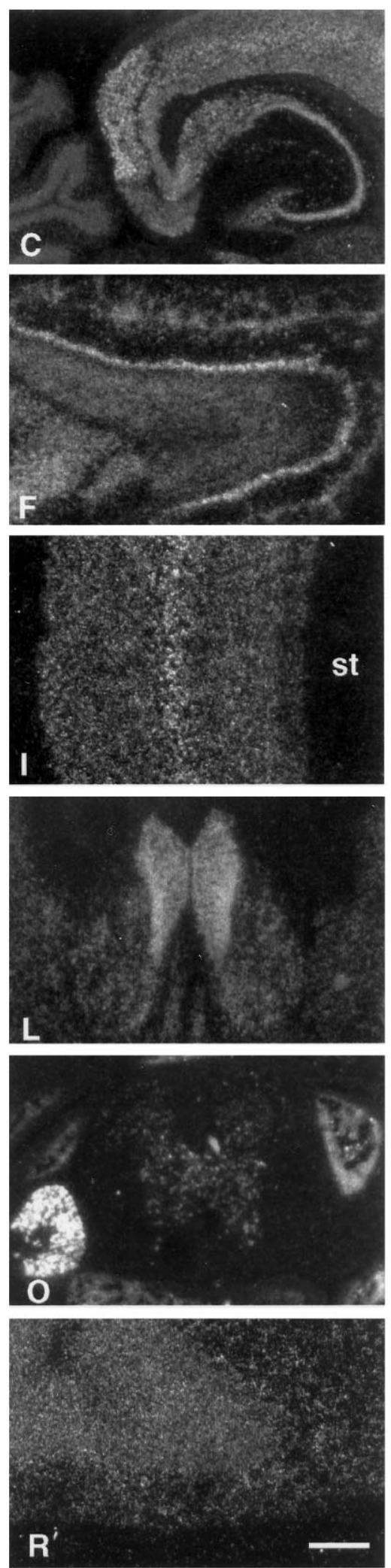

Figure 8. In situ hybridization of $H u$ mRNAs in adult mouse brain and spinal cord. Horizontal sections (11 $\mu$ m) of adult mouse brain and spinal cord were hybridized with ${ }^{33} \mathrm{P}$-labeled antisense probes specific for $m H u B(A, D, G, J, M, P), m H u C(B, E, H, K, N, Q)$, and $m H u D(C, F, I, L, O, R)$ cRNA probes. Hippocampal formation $(\mathrm{Hf})$, olfactory bulb $(\mathrm{Ob})$, cerebral cortex $(\mathrm{Ctx})$, habenula $(\mathrm{Hb})$, spinal cord $(\mathrm{Sc})$, and cerebellum $(\mathrm{Cb})$ are shown. Note that the hybridization signal of $m H u B$ is intense in hippocampal pyramidal cells CA2, CA3, and CA4, mitral cell layer ( $m t)$, accessory olfactory bulb (ao), and dorsal root ganglia, but the signal is absent in the cerebellum except for some scattered cells in the granule cell layer ( $g r$ ). Figure legend continues. 
express $m H u D$. It is possible that individual splice variants of any of the $\mathrm{Hu}$ genes may further subdivide the apparent patterns of expression of any one $H u$ family member into smaller domains. Taken together, these observations suggest that the $m H u$ genes perform nonredundant functions. Moreover, the expression of some $\mathrm{Hu}$ genes in specific domains of the nervous system suggests that they play a role in the development and function of such regions.

\section{Neuronal RNA binding proteins}

One remarkable feature of the current study is the exquisite tissue specificity with which the $H u$ genes are expressed within the nervous system. Most mammalian RNA binding proteins identified have been found to be ubiquitously expressed, including the great majority of RRM-containing proteins (see Birney et al., 1993; Burd and Dreyfuss, 1994). The most significant exceptions to date are three classes of neuron-specific RBPs. The first class, related to the hnRNP K protein (Siomi et al., 1993a; Burd and Dreyfuss, 1994), is exemplified by the paraneoplastic antigen Nova-1 (Buckanovich et al., 1993) and includes the fragile $X$ gene, FMR-1 (Burd and Dreyfuss, 1994). Both Nova-1 and FMR-1 are RNA binding proteins (Siomi et al., 1993b; Buckanovich et al., 1996) believed to be expressed in neurons. However, although FMR-1 is expressed within most neurons, with some regional variation, it also is expressed outside of the nervous system (Abitbol et al., 1993; Devys et al., 1993; Hinds et al., 1993). In contrast, Nova-1 expression is restricted strictly to a subset of CNS neurons (Buckanovich et al., 1993, 1996), indicating that its function is unique to neurons. A second class of RRM containing n-RBPs is related to the hnRNP A/B proteins (Dreyfuss et al., 1993) and includes the Drosophila (Nakamura et al., 1994) and mouse (Sakakibara et al., 1996) musashi proteins and the Xenopus laevis nrp-1 protein (Richter et al., 1990). The nrp-1 and mouse musashi $\mathrm{n}$-RBPs are expressed in the ventricular zone of the developing neural tube, and musashi is required for the proper development of adult sensory organs (Nakamura et al., 1994).

A third class of n-RBPs consists of RRM-containing proteins related to the paraneoplastic $H u$ genes. The closest $H u$ relatives in this class are elav, which is required for neurogenesis in the early embryo (Robinow et al., 1988a,b; Yao et al., 1993), and rbp9, which is expressed at later developmental stages (Kim and Baker, 1993). A third more distantly related protein, cpo, is an RBP for which the expression is restricted primarily to the developing peripheral nervous system, although it also is found in some other tissues (Bellen et al., 1992). Although elav and rbp9 are ubiquitously expressed within the Drosophila nervous system, the $\mathrm{Hu}$ genes show marked variability in both developmental patterns of expression and tissue distribution within the nervous system. We observed a hierarchy of $\mathrm{Hu}$ gene expression in neuronal development and a great heterogeneity of $H u$ gene expression within individual neuronal types in the adult (see Fig. 8). These results suggest that, in contrast to ubiquitously expressed RBPs, the $H u$ genes perform cell-specific roles in individual stages of differentiating neurons and within specific neuronal types. Clarification of those roles awaits identification of the RNA targets of these proteins in neurons.

\section{The $H u$ genes encode a diverse set of disease antigens}

The complexity of expression of the $m H u$ mRNAs not only suggests specific roles for individual family members but has implications for the paraneoplastic $\mathrm{Hu}$ syndrome. The $H u$ genes are the targets of autoimmune attack in the adult brain; antibodies to $\mathrm{HuA}$ (see Fig. 4B), HuB (Dropcho and King, 1994), HuC, and HuD (Szabo et al., 1991; Manley et al., 1995) fusion proteins now have been documented in the sera of $\mathrm{Hu}$ patients. The initiating antigen expressed in small-cell lung cancers is likely to be a subset of the neuronal $\mathrm{Hu}$ antigens. In an RT-PCR analysis of mRNA expression in three PND-associated small-cell lung tumors, $H u D$, but not $H u B(H e l-N 1)$ or $H u C$, gene expression was detected (Manley et al., 1995). It remains unclear, however, which $\mathrm{Hu}$ antigens serve as targets for the autoimmune neurological assault.

It is of interest that some of the patterns of $\mathrm{Hu}$ expression correlate with discrete syndromes of neurological dysfunction seen in many patients presenting with the Hu syndrome (Dalmau et al., 1991). Thus, some Hu patients suffer a pure cerebellar degeneration that cannot be differentiated from typical paraneoplastic cerebellar degeneration in which Purkinje neurons are targeted (Dalmau et al., 1991). Similarly, $5 \%$ of $\mathrm{Hu}$ patients develop a pure limbic encephalopathy referable to hippocampal dysfunction (Dalmau et al., 1991). Although the cellular level of these neurological disorders is uncertain, pure cerebellar symptoms correlate with the exclusive expression of $m H u C$ in Purkinje neurons and the near exclusive expression of $m H u C$ in adult granule cells; similarly, limbic symptoms correlate with specific expression of $\mathrm{HuC}$ in dentate neurons or to the subsets of hippocampal pyramidal neurons expressing only $H u D$ and $H u C$ (see Table 1). Such exclusive vulnerability of some neurons to autoimmune dysfunction might relate to a lack of redundancy of $\mathrm{Hu}$ antigen expression in these neurons. The most common symptom, suffered by $>70 \%$ of $\mathrm{Hu}$ patients (Dalmau et al., 1991; Posner, 1995), is a dorsal root ganglionopathy, which may correlate with the vulnerability of neurons in the peripheral nervous system versus CNS and with the high levels of antigen expression in the adult DRG (see Fig. 8).

Taken together, our data suggest that finer analysis of the neuronal dysfunction in adults may be able to be correlated with targeting of discrete $\mathrm{Hu}$ gene family members in various regions of the nervous system. Conversely, the indiscriminate attack against all $\mathrm{Hu}$ proteins evident in $\mathrm{Hu}$ antisera correlates with the multifocal neurological degeneration that $75 \%$ of $\mathrm{Hu}$ patients ultimately develop (Posner, 1995). The progression of unifocal to multifocal neurological symptoms that occurs in most of these patients may correspond to a progression of autoimmune targeting of specific $\mathrm{Hu}$ epitopes to a targeting of common $\mathrm{Hu}$ epitopes.

\section{Conclusions: complexity of the Hu RNA binding proteins}

Our work illustrates several levels of complexity in the family of $\mathrm{Hu}$ RNA binding proteins. First, analysis of alternative splice variants suggests that at least 18 different $\mathrm{Hu}$ proteins are encoded by four genes. Second, the regulation of expression of each gene (and perhaps each subtype of spliced gene product) seems likely

\footnotetext{
The mRNA of $m H u C$ is widely expressed in the adult nervous system, including hippocampal dentate gyrus $(d g)$, pyramidal cells, glomerular $(g l)$, mitral and granule cell layer $(\mathrm{gr})$ of olfactory bulb, cortex, corpus striatum $(\mathrm{st})$, medial habenula $(\mathrm{mh})$, gray $(\mathrm{gm})$ and white matter $(w m)$ of spinal cord, dorsal root ganglia $(d r g)$, and Purkinje cells $(p)$. $m H u D$ expression is prominent in the entorhinal cortex (er), medial habenula, and dorsal root ganglia, but it is absent in dentate gyrus, corpus striatum, and Purkinje cells. No reactivity was observed with sense riboprobes (data not shown). $v$, Third ventricle; $m o l$, molecular layer. Scale bars: $400 \mu \mathrm{m}$ in $A-C ; 300 \mu \mathrm{m}$ in $D-F ; 200 \mu \mathrm{m}$ in $G-I ; 300 \mu \mathrm{m}$ in $J-L ; 400 \mu \mathrm{m}$ in $M-O ; 100 \mu \mathrm{m}$ in $P-R$.
} 
Table 2. Summary of differential expression of mouse $\mathrm{Hu}$ genes by in situ hybridization studies

\begin{tabular}{|c|c|c|c|c|}
\hline & Hи A & $H u B$ & $\mathrm{HuC}$ & $H u D$ \\
\hline \multicolumn{5}{|l|}{ E16: } \\
\hline Retina & ++ & +++ & +++ & +++ \\
\hline Neocortex & + & ++ & +++ & + \\
\hline Corpus striatum & + & - & ++ & - \\
\hline Thalamus & - & +++ & +++ & +++ \\
\hline Hypothalamus & - & +++ & +++ & ++ \\
\hline Midbrain & $+/-$ & +++ & +++ & + \\
\hline Cerebellum & ++ & + & +++ & $+/-$ \\
\hline Pons & + & +++ & +++ & +++ \\
\hline Spinal cord-dorsal & + & +++ & +++ & +++ \\
\hline ventral & + & ++ & +++ & +++ \\
\hline Dorsal root ganglia & + & +++ & +++ & +++ \\
\hline \multicolumn{5}{|l|}{ PO: } \\
\hline Nasal epithelium & + & + & +++ & +++ \\
\hline Olfactory bulb & + & ++ & +++ & +++ \\
\hline Trigeminal ganglia & ++ & +++ & +++ & +++ \\
\hline Retina & $+1-$ & $+1-$ & +++ & + \\
\hline Cerebral cortex & + & $+/-$ & +++ & + \\
\hline Hippocampus-pyamidal cells & ++ & ++ & +++ & ++ \\
\hline granule cells & ++ & - & ++ & - \\
\hline Corpus striatum & + & - & +++ & - \\
\hline Thalamus & - & ++ & +++ & + \\
\hline Hypothalamus & + & ++ & ++ & ++ \\
\hline Midbrain & $+/-$ & ++ & +++ & + \\
\hline Cerebellum-Purkinje cells & + & - & +++ & - \\
\hline EGL & + & +++ & ++ & + \\
\hline IGL & - & - & +++ & ++ \\
\hline Pons & $+/-$ & ++ & +++ & ++ \\
\hline Spinal cord-dorsal & + & ++ & +++ & ++ \\
\hline ventral & + & + & +++ & + \\
\hline Dorsal root ganglia & ++ & +++ & +++ & +++ \\
\hline Sympathetic ganglia & + & +++ & +++ & +++ \\
\hline \multicolumn{5}{|l|}{ Adult: } \\
\hline Olfactory bulb-mitral cells & $+/-$ & ++ & ++ & ++ \\
\hline granule cells & - & - & ++ & + \\
\hline Cerebral cortex & + & $+/-$ & +++ & ++ \\
\hline Hippocampus-CA 1 & ++ & - & +++ & ++ \\
\hline CA 2 & ++ & ++ & +++ & ++ \\
\hline CA 3,4 & ++ & +++ & +++ & ++ \\
\hline granule cells & + & - & +++ & - \\
\hline Entorhinal cortex & $+/-$ & - & ++ & +++ \\
\hline Corpus striatum & $+/-$ & - & ++ & - \\
\hline Thalamus & - & ++ & +++ & + \\
\hline Hypothalamus & $+/-$ & ++ & ++ & $+/-$ \\
\hline Habenula & ++ & - & +++ & +++ \\
\hline Amygdala & - & + & +++ & ++ \\
\hline Midbrain & $+/-$ & + & ++ & $+/-$ \\
\hline Cerebellum-Purkinje cells & + & - & +++ & - \\
\hline granule cells & - & - & +++ & + \\
\hline Pons & $+/-$ & ++ & +++ & ++ \\
\hline Olivary nucleus & - & - & +++ & +++ \\
\hline Spinal cord-dorsal & $+/-$ & ++ & +++ & ++ \\
\hline ventral & - & + & +++ & + \\
\hline Dorsal root ganglia & ++ & +++ & +++ & +++ \\
\hline
\end{tabular}

+++ , Dark signal; ++ , average signal; + , weak signal; $+/-$, very weak signal; - , undetectable signal. to be regulated at both the transcriptional and posttranscriptional levels on the basis of our finding multiple alternate 5' and 3' UTR variants as well as direct evidence of posttranscriptional regulation of $\mathrm{mHuA}$ expression. Third, within any one neuron it is apparent that different combinations of $\mathrm{Hu}$ genes are expressed. This is well illustrated in both developing neurons, such as those in the cortex and cerebellum, and in the adult, where there is differential expression of $m H u$ genes in the many regions, including the hippocampus, cerebellum, neocortex, and olfactory bulb. Loss-of-function experiments may be able to test the prediction that such hierarchies of expression of different $H u$ gene products are responsible for some aspect of complexity within these different neuronal groups.

\section{REFERENCES}

Abe R, Yamamoto K, Sakamoto H (1996) Target specificity of neuronal RNA-binding protein, Hel-N1: direct binding to the $3^{\prime}$ untranslated region of its own mRNA. Nucleic Acids Res 24:2011-2016.

Abitbol M, Menini C, Delezoide A, Rhyner T, Vekemans M, Mallet J (1993) Nucleus basalis magnocellularis and hippocampus are the major sites of FMR-1 expression in the human fetal brain. Nat Genet 4:147-153.

Arning S, Grüter P, Bilbe G, Kramer A (1996) Mammalian splicing factor SF1 is encoded by variant cDNAs and binds to RNA. RNA 2:794-810.

Barami K, Iversen K, Furneaux H, Goldman SA (1995) Hu protein as an early marker of neuronal phenotypic differentiation by subependymal zone cells of the adult songbird forebrain. J Neurobiol 28:82-101.

Bellen HJ, Kooyer S, D'Evelyn D, Pearlman J (1992) The Drosophila couch potato protein is expressed in nuclei of peripheral neuronal precursors and shows homology to RNA-binding proteins. Genes Dev 6:2125-2136.

Birney E, Kuman S, Krainer AR (1993) Analysis of the RNA-recognition motif and RS and RGG domains: conservation in metazoan pre-mRNA splicing factors. Nucleic Acids Res 21:5803-5816.

Buckanovich RJ, Posner JB, Darnell RB (1993) Nova, the paraneoplastic $\mathrm{Ri}$ antigen, is homologous to an RNA-binding protein and is specifically expressed in the developing motor system. Neuron 11:657-672.

Buckanovich RJ, Yang YY, Darnell RB (1996) The onconeural antigen Nova-1 is a neuron-specific RNA binding protein, the activity of which is inhibited by paraneoplastic antibodies. J Neurosci 16:1114-1122.

Burd CG, Dreyfuss G (1994) Conserved structures and diversity of functions of RNA-binding proteins. Science 265:615-621.

Chomcynski P, Sacchi N (1987) Single-step method of RNA isolation by acid guanidinium thiocyanate-phenol-chloroform extraction. Anal Biochem 162:156-159.

Corradi JP, Yang CW, Darnell JC, Dalmau J, Darnell RB (1997) A post-transcriptional regulatory mechanism restricts expression of the paraneoplastic cerebellar degeneration antigen cdr2 to immune privileged tissues. J Neurosci 17:1406-1415.

Dalmau J, Graus F, Rosenblum MK, Posner JB (1991) Anti-Hu associated paraneoplastic encephalomyelitis/sensory neuropathy: a clinical study of 71 patients. Medicine (Baltimore) 71:59-72.

Dalmau J, Furneaux HM, Cordon-Cardo C, Posner JB (1992) The expression of the $\mathrm{Hu}$ (paraneoplastic encephalomyelitis/sensory neuronopathy) antigen in human normal and tumor tissues. Am J Pathol 141:881-886.

Darnell RB (1996) Onconeural antigens and the paraneoplastic neurologic disorders: at the intersection of cancer, immunity, and the brain. Proc Natl Acad Sci USA 93:4529-4536.

Devys D, Lutz Y, Rouyer N, Bellocq J, Mandel J (1993) The FMR-1 protein is cytoplasmic, most abundant in neurons, and appears normal in carriers of a fragile $X$ permutation. Nat Genet 4:335-340.

Dreyfuss G, Matunis MJ, Piñol-Roma S, Burd CG (1993) hnRNP proteins and the biogenesis of mRNA. Annu Rev Biochem 62:289-321.

Dropcho EJ, King PH (1994) Autoantibodies against the Hel-N1 RNAbinding protein among patients with lung carcinoma: an association with type I anti-neuronal nuclear antibodies. Ann Neurol 36:200-205.

Fujita S (1967) Quantitative analysis of cell proliferation and differentiation in the cortex of the postnatal mouse cerebellum. J Cell Biol 32:277-287.

Gao FB, Carson CC, Levine T, Keene JD (1994) Selection of a subset of 
mRNAs from combinatorial 3' untranslated region libraries using neuronal RNA-binding protein Hel-N1. Proc Natl Acad Sci USA 91:11207-11211.

Gibbs RB, Pfaff DW (1994) In situ hybridization detection of trkA mRNA in brain: distribution, co-localization with p75NGFR, and upregulation by nerve growth factor. J Comp Neurol 341:324-339.

Good PJ (1995) A conserved family of elav-like genes in vertebrates. Proc Natl Acad Sci USA 92:4557-4561.

Graus F, Cordon-Cardo C, Posner J (1985) Neuronal antinuclear antibody in sensory neuronopathy from lung cancer. Neurology 35:538-543.

Hinds HL, Ashley CT, Sutcliffe JS, Nelson DL, Warren ST, Housman DE Schalling M (1993) Tissue-specific expression of FMR-1 provides evidence for a functional role in fragile $X$ syndrome. Nat Genet 3:36-43.

Imataka H, Nakayama K, Yasumoto K, Mizuno A, Fujii-Kuriyama Y, Hayami M (1994) Cell-specific translational control of transcription factor BTEB expression. J Biol Chem 269:20668-20673.

Kim Y-J, Baker B (1993) The Drosophila gene rbp9 encodes a protein that is a member of a conserved group of putative RNA binding proteins that are nervous system-specific in both flies and humans. J Neurosci 13:1045-1056.

King PH, Levine TD, Fremeau RT, Keene JD (1994) Mammalian homologs of Drosophila ELAV localized to a neuronal subset can bind in vitro to the 3' UTR of mRNA encoding the Id transcriptional repressor. J Neurosci 14:1943-1952.

Lagnado CA, Brown CY, Goodall GJ (1994) AUUUA is not sufficient to promote poly $\left(\mathrm{A}^{+}\right)$shortening and degradation of an mRNA: the functional sequence within AU-rich elements may be UUAUUUA(U/A)(U/ A). Mol Cell Biol 14:7984-7995.

Levine TD, Gao F, King PH, Andrews LG, Keene JD (1993) Hel-N1: an autoimmune RNA-binding protein with specificity for $3^{\prime}$ uridylate-rich untranslated regions of growth factor mRNAs. Mol Cell Biol 13:3494-3504.

Liu J, Dalmau J, Szabo A, Rosenfeld M, Huber J, Furneaux H (1995) Paraneoplastic encephalomyelitis antigens bind to the AU-rich elements of mRNA. Neurology 45:544-550.

Ma W, Cheng S, Campbell C, Wright A, Furneaux H (1996) Cloning and characterization of $\mathrm{HuR}$, a ubiquitously expressed elav-like protein. J Biol Chem 271:8144-8151.

Manley GT, Smitt PS, Dalmau J, Posner JB (1995) Hu antigens: reactivity with $\mathrm{Hu}$ antibodies, tumor expression, and major immunogenic sites. Ann Neurol 38:102-110.

Marusich MF, Furneaux HM, Henion PD, Weston JA (1994) Hu neuronal proteins are expressed in proliferating neurogenic cells. J Neurobiol 25:143-155.

McMullough AJ, Schuler MA (1993) AU-rich intronic elements affect pre-mRNA 5' splice site selection in Drosophila melanogaster. Mol Cell Biol 13:7689-7697.

Miale I, Sidman RL (1961) An autoradiographic analysis of histogenesis in the mouse cerebellum. Exp Neurol 4:227-296.

Min H, Turck CW, Black DL (1996) A new regulatory protein, KSR, mediates exon inclusion through an intronic splicing enhancer. Genes Dev, in press.
Nakamura M, Okano H, Blendy JA, Montell C (1994) Musashi, a neural RNA-binding protein required for Drosophila adult external sensory organ development. Neuron 13:67-81.

Posner JB (1995) Anti-Hu autoantibody-associated sensory neuropathy/ encephalomyelitis: a model of paraneoplastic syndrome. Perspect Biol Med 38:167-181.

Posner JB, Furneaux HM (1990) Paraneoplastic syndromes. In: Immunologic mechanisms in neurologic and psychiatric disease (Waksman BH, ed), pp 187-219. New York: Raven.

Richter K, Good PJ, Dawid IB (1990) A developmentally regulated, nervous system-specific gene in Xenopus encodes a putative RNAbinding protein. New Biol 2:556-565.

Robinow S, Campos A, Yao K, White K (1988a) The elav gene product of Drosophila, required in neurons, has three RNP consensus motifs. Science 242:1570-1572.

Robinow S, Campos A, Yao K, White K (1988b) The locus Elav of Drosophila melanogaster is expressed in neurons at all developmental stages. Dev Biol 126:294-303.

Sakai K, Gofuku M, Kitagawa Y, Ogasawara T, Hirose G, Yamazaki M, Koh CS, Yanagisawa N, Steinman L (1993) A hippocampal protein associated with paraneoplastic neurologic syndrome and small cell lung carcinoma. Biochem Biophys Res Commun 199:1200-1208.

Sakakibara S, Imai T, Hamaguchi K, Okabe M, Aruga J, Nakajima K, Yasutomi D, Nagata T, Kurihara Y, Uesugi S, Miyata T, Ogawa M, Mikoshiba K, Okano H (1996) Mouse musashi-1, a neural RNA binding protein highly enriched in the mammalian CNS stem cell. Dev Biol 176:230-242.

Shaw G, Kamen R (1986) A conserved AU sequence from the 3' untranslated region of GM-CSF mRNA mediates selective mRNA degradation. Cell 46:659-667.

Siomi H, Matunis MJ, Michael WM, Dreyfuss G (1993a) The premRNA binding $\mathrm{K}$ protein contains a novel evolutionarily conserved motif. Nucleic Acids Res 21:1193-1198.

Siomi H, Siomi M, Nussbaum R, Dreyfuss G (1993b) The protein product of the fragile $X$ gene, FMR-1, has characteristics of an RNA-binding protein. Cell 74:291-298.

Szabo A, Dalmau J, Manley G, Rosenfeld M, Wong E, Henson J, Posner JB, Furneaux HM (1991) HuD, a paraneoplastic encephalomyelitis antigen, contains RNA-binding domains and is homologous to Elav and sex lethal. Cell 67:325-333.

Ullrich B, Ushkaryov YA, Sudhof TC (1995) Cartography of neurexins: more than 1000 isoforms generated by alternative splicing and expressed in distinct subsets of neurons. Neuron 14:497-507.

Waid DK, McLoon SC (1995) Immediate differentiation of ganglion cells following mitosis in the developing retina. Neuron 14:117-124.

Yao K-M, Samson M-L, Reeves R, White K (1993) Gene elav of Drosophila melanogaster: a prototype for neuronal-specific RNA binding protein gene family that is conserved in flies and humans. J Neurobiol 24:723-739.

Zubiaga AM, Belasco JG, Greenberg ME (1995) The nonamer UUAUUUAUU is the key AU-rich sequence motif that mediates mRNA degradation. Mol Cell Biol 15:2219-2230. 